\title{
Programmable Repurposing of Existing Drugs as Pharmaceutical Elements for the Construction of Aptamer-Drug Conjugates
}

Fei Gao", Jinming Zhoü, Yang Sun, Cai Yang, Shiyan Zhang, Ruowen Wang and Weihong $\operatorname{Tan}^{*}$

[a] Dr. F. Gao, Dr. Y. Sun, C. Yang, S. Zhang, Prof. Dr. R. Wang, Prof. Dr. W, Tan

Institute of Molecular Medicine (IMM), State Key Laboratory of Oncogenes and Related Genes, Renji Hospital, Shanghai Jiao Tong University School of Medicine, and College of Chemistry and Chemical Engineering, Shanghai Jiao Tong University, Shanghai 200240, China

[b] Dr. F. Gao

Institute of Translation Medicine, Shanghai University,

Shanghai 200444, China

[c] Prof. Dr. J. Zhou

Key Laboratory of the Ministry of Education for Advanced Catalysis Materials, Department of Chemistry, Zhejiang Normal University,

Jinhua 321004, China

[d] Prof. Dr. W, Tan

The Cancer Hospital of the University of Chinese Academy of Sciences, Institute of Basic Medicine and Cancer (IBMC), Chinese Academy of Sciences, Hangzhou, Zhejiang 310022, China

\section{Table of Contents}

1. General Information

2. Synthesis of Pharmaceutical Modules...

3. Cell Viability of Precursor 1, 2 and $\mathbf{3}$ S9-S10

4. ApDCs Synthesis and Mass Spectra $\mathrm{S} 10-\mathrm{S} 11$

5. Experiments on ApDCs Stability S11

6. Copies of NMR Spetra $. \mathrm{S} 12-\mathrm{S} 23$ 


\section{General Information}

Synthetic information: All starting materials were purchased from commercial sources without further purification. Glassware was dried in oven and cooled before use. All reactions were monitored by TLC and visualized by UV lamp ( $254 \mathrm{~nm}$ or $365 \mathrm{~nm})$. Yields generally referred to chromatographically isolated yields, unless otherwise noted. ${ }^{1} \mathrm{H}$ NMR, ${ }^{13} \mathrm{C}$ NMR and ${ }^{31} \mathrm{P}$ NMR spectra were recorded in DMSO- $\mathrm{d}_{6}, \mathrm{CDCl}_{3}, \mathrm{CD}_{3} \mathrm{OD}$, or $\mathrm{CD}_{3} \mathrm{CN}$ on a Varian $500 \mathrm{MHz}$ instrument. For ${ }^{1} \mathrm{H}$ NMR (500MHz), DMSO-d 6 ( $\left.\delta=2.50 \mathrm{ppm}\right), \mathrm{CDCl}_{3}(\delta=7.26 \mathrm{ppm}), \mathrm{CD}_{3} \mathrm{OD}(\delta=3.31 \mathrm{ppm})$ or $\mathrm{CD}_{3} \mathrm{CN}(\delta=1.96 \mathrm{ppm})$ served as internal standard, and data are reported as follows: chemical shift $($ in $\mathrm{ppm})$, multiplicity $(\mathrm{s}=$ singlet, $\mathrm{d}=$ doublet, $\mathrm{t}=$ triplet, $\mathrm{q}=$ quartet, $\mathrm{m}=$ multiplet, brs $=$ broad singlet), coupling constant (in Hz), and integration. HRMS (ESI) spectra were recorded on a Thermo Scientific Q Exactive HF Orbitrap-FTM. Flash column chromatography was performed using 200-300 mesh silica gel.

Cell culture: HCT116 cells and Ramos cells were obtained from the China Center for Type Culture Collection (CCTCC, China). The cells were maintained in RPMI-1640 medium, supplemented with $10 \%$ fetal bovine serum (FBS) and $1 \%$ penicillin-streptomycin (Cellgro) and incubated at $37{ }^{\circ} \mathrm{C}$ in a humid atmosphere with $5 \% \mathrm{CO}_{2}$. The cell lines were negative for mycoplasma.

\section{Synthesis of Pharmaceutical Modules}

Scheme S1. Synthesis of compound 1

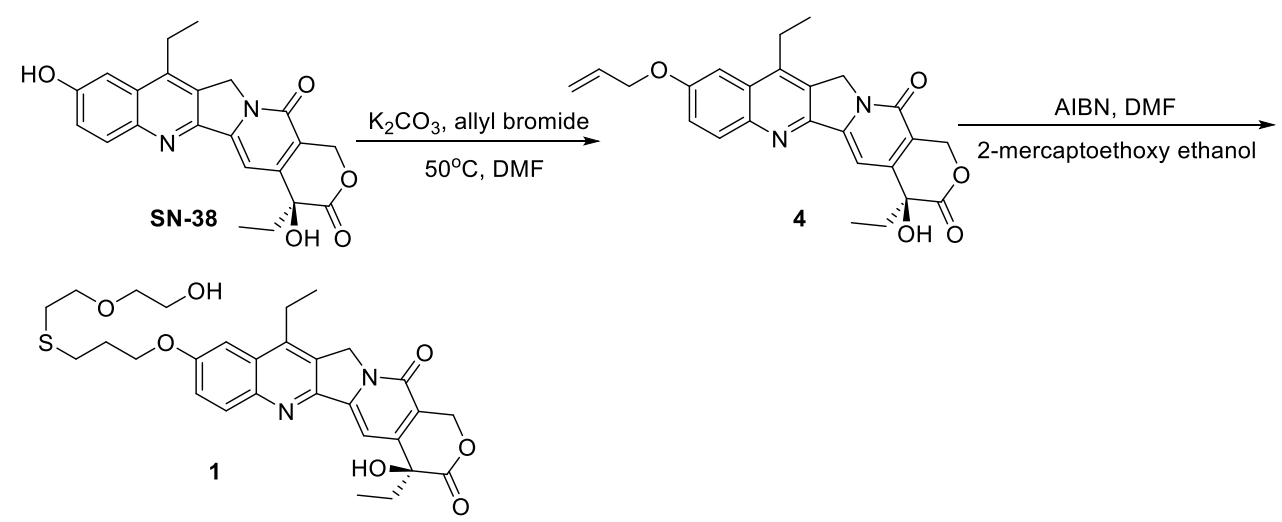

Step 1 : To a stirred solution of SN-38 (1.200 g, $3.1 \mathrm{mmol}, 1.0$ equiv) in dry DMF (15 mL) were added $\mathrm{K}_{2} \mathrm{CO}_{3}(0.643 \mathrm{~g}, 4.65 \mathrm{mmol}, 1.5$ equiv) and ally bromide $(0.750 \mathrm{~g}, 6.2 \mathrm{mmol}, 2.0$ equiv). The mixture was heated to $50{ }^{\circ} \mathrm{C}$ for $3 \mathrm{~h}$. When the consumption of SN-38 completed as monitored by TLC, the mixture was poured into ice water. Then, diluted hydrochloric acid was added to adjust the $\mathrm{pH}$ to 5 . The yellow solid which precipitated from the solution was collected and washed with 
cold water 3 times giving compound 4 as a yellow solid $(1.070 \mathrm{~g}, 81 \%$ yield). Yellow soild, $\mathrm{mp}=$ 252.1-257.7 ${ }^{\circ} \mathrm{C} .{ }^{1} \mathbf{H}$ NMR $\left(500 \mathrm{MHz}, \mathrm{CDCl}_{3}\right) \delta_{\mathrm{H}} 8.14(\mathrm{~d}, J=9.2 \mathrm{~Hz}, 1 \mathrm{H}), 7.63(\mathrm{~s}, 1 \mathrm{H}), 7.46(\mathrm{dd}, J$ $=9.2,2.7 \mathrm{~Hz}, 1 \mathrm{H}), 7.29(\mathrm{~d}, J=2.5 \mathrm{~Hz}, 1 \mathrm{H}), 6.20-6.11(\mathrm{~m}, 1 \mathrm{H}), 5.74(\mathrm{~d}, J=16.2 \mathrm{~Hz}, 1 \mathrm{H}), 5.54(\mathrm{dd}$, $J=17.3,1.4 \mathrm{~Hz}, 1 \mathrm{H}), 5.41(\mathrm{dd}, J=10.5,1.2 \mathrm{~Hz}, 1 \mathrm{H}), 5.29(\mathrm{~d}, J=16.2 \mathrm{~Hz}, 1 \mathrm{H}), 5.21(\mathrm{~d}, J=2.5 \mathrm{~Hz}$, 2H), $4.73(\mathrm{~d}, J=5.3 \mathrm{~Hz}, 2 \mathrm{H}), 4.12(\mathrm{~s}, 1 \mathrm{H}), 3.12(\mathrm{q}, J=7.5 \mathrm{~Hz}, 2 \mathrm{H}), 1.96-1.85(\mathrm{~m}, 2 \mathrm{H}), 1.40(\mathrm{t}, J=$ $7.7 \mathrm{~Hz}, 3 \mathrm{H}), 1.03(\mathrm{t}, J=7.4 \mathrm{~Hz}, 3 \mathrm{H}) ;{ }^{13} \mathbf{C} \mathbf{N M R}\left(126 \mathrm{MHz}, \mathrm{CDCl}_{3}\right) \delta_{\mathrm{c}} 173.9,157.7,157.6,150.2$, 149.6, 147.2, 145.3, 143.6, 132.7, 132.1, 128.1, 127.2, 122.6, 118.4, 117.9, 102.9, 97.4, 72.8, 69.2, 66.3, 49.4, 31.6, 23.2, 13.6, 7.9; IR: $\bar{v}=3375,2920,1753,1653,1593,1259,805 ; \mathbf{H R M S ~ m / z ~ ( E S I ) ~}$ calcd for $\mathrm{C}_{25} \mathrm{H}_{25} \mathrm{~N}_{2} \mathrm{O}_{5}^{+}[\mathrm{M}+\mathrm{H}]^{+}: 433.1758$, found: 433.1755 .

Step 2: To a stirred solution of compound $4(0.500 \mathrm{~g}, 1.2 \mathrm{mmol}, 1.0$ equiv) in dry DMF (10 mL) were added AIBN $(0.100 \mathrm{~g}, 0.6 \mathrm{mmol}, 0.5$ equiv) and 2-mercaptoethoxy ethanol ( $0.733 \mathrm{~g}, 6.0 \mathrm{mmol}$, 5.0 equiv). The reaction mixture was heated to $80^{\circ} \mathrm{C}$ under $\mathrm{N}_{2}$ atmosphere. Upon full consumption of compound 4, the reaction mixture was poured into water, eluting with EtOAc $(3 \mathrm{x})$. The combined organic phases were dried over $\mathrm{Na}_{2} \mathrm{SO}_{4}$ and concentrated in vacuo. The residue was purified by silica gel flash column chromatography (DCM/MeOH) to afford compound $\mathbf{1}(0.400 \mathrm{~g}, 62 \%$ yield). Yellow oil. ${ }^{1} \mathbf{H}$ NMR $\left(500 \mathrm{MHz}, \mathrm{CDCl}_{3}\right) \delta_{\mathrm{H}} 8.13(\mathrm{~d}, J=9.2 \mathrm{~Hz}, 1 \mathrm{H}), 7.62(\mathrm{~s}, 1 \mathrm{H}), 7.44(\mathrm{dd}, J=9.2$, $2.6 \mathrm{~Hz}, 1 \mathrm{H}), 7.29$ (d, $J=2.5 \mathrm{~Hz}, 1 \mathrm{H}), 5.74(\mathrm{~d}, J=16.2 \mathrm{~Hz}, 1 \mathrm{H}), 5.30$ (d, $J=16.1 \mathrm{~Hz}, 1 \mathrm{H}), 5.22(\mathrm{~s}$, 2H), $4.25(\mathrm{t}, J=6.0 \mathrm{~Hz}, 2 \mathrm{H}), 3.78-3.75(\mathrm{~m}, 2 \mathrm{H}), 3.73(\mathrm{t}, J=6.5 \mathrm{~Hz}, 2 \mathrm{H}), 3.64-3.58(\mathrm{~m}, 2 \mathrm{H}), 3.17-$ $3.11(\mathrm{~m}, 2 \mathrm{H}), 2.86(\mathrm{t}, J=7.1 \mathrm{~Hz}, 2 \mathrm{H}), 2.81(\mathrm{t}, J=6.5 \mathrm{~Hz}, 2 \mathrm{H}), 2.24-2.16(\mathrm{~m}, 2 \mathrm{H}), 1.95-1.86(\mathrm{~m}$, 4H), $1.41(\mathrm{t}, J=7.7 \mathrm{~Hz}, 3 \mathrm{H}), 1.03(\mathrm{t}, J=7.4 \mathrm{~Hz}, 3 \mathrm{H}) ;{ }^{13} \mathbf{C ~ N M R}\left(126 \mathrm{MHz}, \mathrm{CDCl}_{3}\right) \delta_{\mathrm{C}} 173.9,158.1$, 157.7, 150.3, 149.6, 147.3, 145.4, 143.7, 132.1, 128.2, 127.2, 122.6, 117.8, 102.5, 97.5, 72.8, 72.1, 70.6, 66.6, 66.3, 61.8, 49.4, 31.9, 31.6, 29.2, 29.1, 23.1, 13.6, 7.8; IR: $\bar{v}=3415,2901,1738,1669$, 1596, 1210, 1028, 844, 732; HRMS m/z (ESI) calcd for $\mathrm{C}_{29} \mathrm{H}_{35} \mathrm{~N}_{2} \mathrm{O}_{7} \mathrm{~S}^{+}[\mathrm{M}+\mathrm{H}]^{+}: 555.2159$, found: 555.2159 .

Scheme S2. Synthesis of compound 2

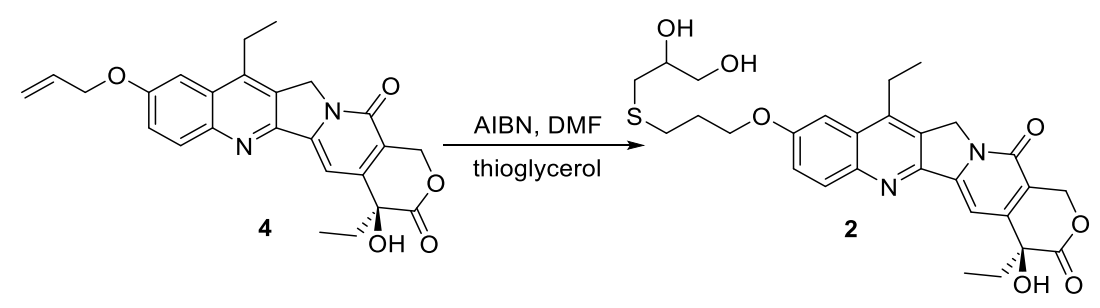


Compound $\mathbf{4}$ was synthesized according to the above procedure. To a stirred solution of compound $4(0.500 \mathrm{~g}, 1.2 \mathrm{mmol}, 1.0$ equiv $)$ in dry DMF $(10 \mathrm{~mL})$ were added AIBN $(0.100 \mathrm{~g}, 0.6 \mathrm{mmol}, 0.5$ equiv) and thioglycerol $\left(0.627 \mathrm{~g}, 6.0 \mathrm{mmol}, 5.0\right.$ equiv). The reaction mixture was heated to $80{ }^{\circ} \mathrm{C}$ under $\mathrm{N}_{2}$ atmosphere. Upon full consumption of compound $\mathbf{4}$, the reaction mixture was poured into water, eluting with EtOAc $(3 \mathrm{x})$. The combined organic phases were dried over $\mathrm{Na}_{2} \mathrm{SO}_{4}$ and concentrated in vасио. The residue was purified by silica gel flash column chromatography (DCM/MeOH) to afford the compound $2\left(0.310 \mathrm{~g}, 50 \%\right.$ yield). Yellow oil. ${ }^{1} \mathbf{H}$ NMR $(500 \mathrm{MHz}$, MeOD) $\delta_{\mathrm{H}} 7.78(\mathrm{~d}, J=9.2 \mathrm{~Hz}, 1 \mathrm{H}), 7.40(\mathrm{~s}, 1 \mathrm{H}), 7.28(\mathrm{dd}, J=9.2,2.6 \mathrm{~Hz}, 1 \mathrm{H}), 7.15(\mathrm{~d}, J=2.6 \mathrm{~Hz}$, 1H), $5.51(\mathrm{~d}, J=16.0 \mathrm{~Hz}, 1 \mathrm{H}), 5.32$ (d, $J=16.0 \mathrm{~Hz}, 1 \mathrm{H}), 5.00-4.89(\mathrm{~m}, 2 \mathrm{H}), 4.21-4.13(\mathrm{~m}, 2 \mathrm{H})$, 3.84-3.78 (m, 1H), 3.62-3.66 (m, 1H), 3.62-3.57 (m, 1H), 3.04 (q, $J=7.8 \mathrm{~Hz}, 2 \mathrm{H}), 2.84$ (t, $J=7.1$ $\mathrm{Hz}, 2 \mathrm{H}), 2.82-2.77(\mathrm{~m}, 1 \mathrm{H}), 2.69-2.62(\mathrm{~m}, 1 \mathrm{H}), 2.19-2.12(\mathrm{~m}, 2 \mathrm{H}), 1.97-1.92(\mathrm{~m}, 2 \mathrm{H}), 1.34(\mathrm{t}, J=$ $7.7 \mathrm{~Hz}, 3 \mathrm{H}), 1.02(\mathrm{t}, J=7.4 \mathrm{~Hz}, 3 \mathrm{H}) ;{ }^{13} \mathbf{C}$ NMR $(126 \mathrm{MHz}, \mathrm{MeOD}) \delta_{\mathrm{C}} 173.4,158.0,157.5,151.1$, $148.6,146.3,144.2,144.1,130.5,127.9,127.3,122.5,118.2,102.0,97.4,72.8,71.5,66.5,65.3$, 64.6, 49.1, 35.0, 30.8, 29.0, 28.7, 22.5, 12.4, 6.8; IR: $\bar{v}=3433,2972,1725,1647,1600,1212,1042$, 846, 738; HRMS m/z (ESI) calcd for $\mathrm{C}_{28} \mathrm{H}_{33} \mathrm{~N}_{2} \mathrm{O}_{7} \mathrm{~S}^{+}[\mathrm{M}+\mathrm{H}]^{+}$: 541.2003, found: 541.2003 .

Scheme S3. Synthesis of compound 3

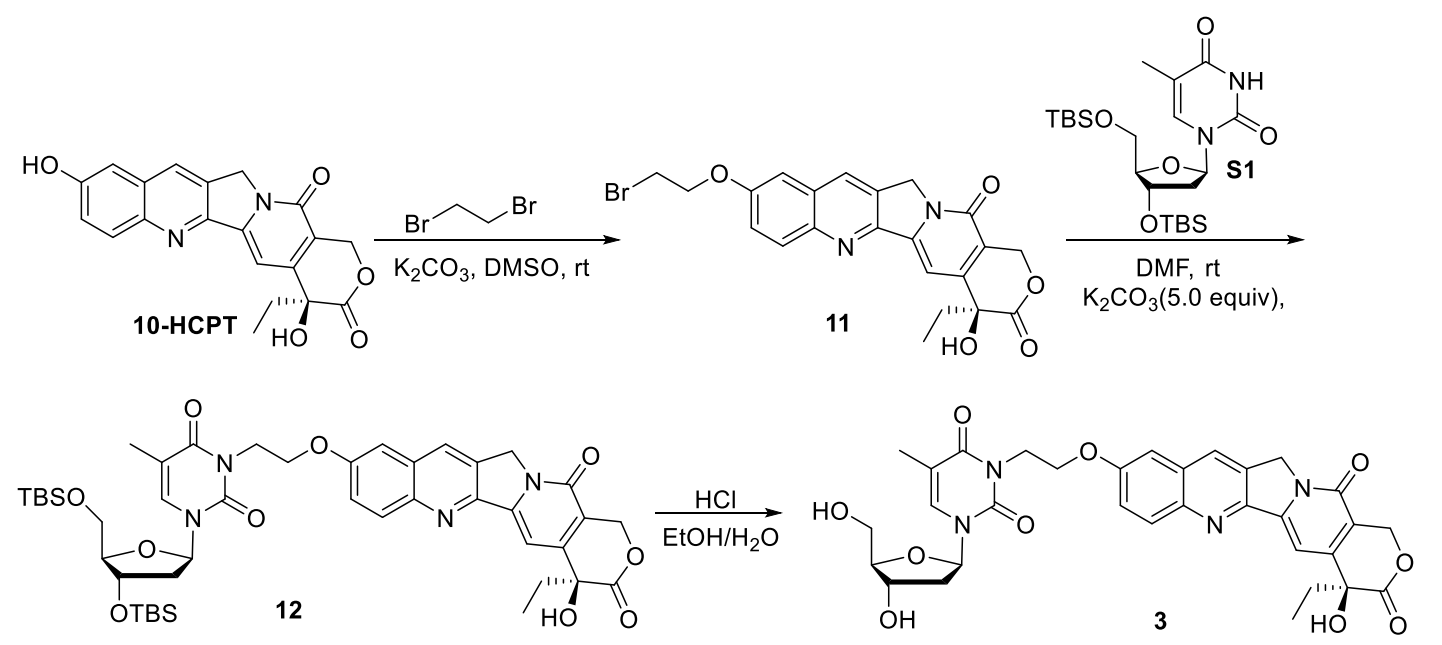

Step 1: To a stirred solution of 10-HCPT (1.100 g, $3.0 \mathrm{mmol}, 1.0$ equiv) in dry DMSO (15 mL) were added $\mathrm{K}_{2} \mathrm{CO}_{3}(1.244 \mathrm{~g}, 9.0 \mathrm{mmol}, 3.0$ equiv) and ally bromide (2.788 g, $15.0 \mathrm{mmol}, 5.0$ equiv). The reaction mixture was stirred overnight at ambient temperature. When the consumption of 10HCPT completed, as monitored by TLC, the mixture was poured into ice water. Then, diluted hydrochloric acid was added to adjust the $\mathrm{pH}$ to 5 . The yellow solid which precipitated from the solution was collected and washed with cold water giving crude product. The crude product was 
purified by silica gel flash column chromatography $(\mathrm{DCM} / \mathrm{MeOH})$ to afford compound $\mathbf{1 1}(1.020 \mathrm{~g}$, $72 \%$ yield). Yellow soild, $\mathrm{mp}=257.6-259.1{ }^{\circ} \mathrm{C} .{ }^{1} \mathbf{H}$ NMR (500 MHz, DMSO) $\delta_{\mathrm{H}} 8.49(\mathrm{~s}, 1 \mathrm{H}), 8.05$ $(\mathrm{d}, J=9.2 \mathrm{~Hz}, 1 \mathrm{H}), 7.55-7.47(\mathrm{~m}, 2 \mathrm{H}), 7.26(\mathrm{~s}, 1 \mathrm{H}), 6.53(\mathrm{~s}, 1 \mathrm{H}), 5.42(\mathrm{~s}, 2 \mathrm{H}), 5.22(\mathrm{~s}, 2 \mathrm{H}), 4.52-$ $4.48(\mathrm{~m}, 2 \mathrm{H}), 3.94-3.91(\mathrm{~m}, 2 \mathrm{H}), 1.91-1.82(\mathrm{~m}, 2 \mathrm{H}), 0.89(\mathrm{t}, J=7.3 \mathrm{~Hz}, 3 \mathrm{H}) ;{ }^{13} \mathbf{C} \mathbf{N M R}(126 \mathrm{MHz}$, DMSO) $\delta_{\mathrm{c}} 173.0,157.2,157.1,150.8,150.5,146.1,144.5,131.1,130.7,130.5,129.7,123.4,118.9$, 107.7, 96.6, 72.9, 68.7, 65.7, 50.7, 31.6, 30.7, 8.3; IR: $\bar{v}=3395,2930,1754,1658,1598,1237$, 1152, 828; HRMS m/z (ESI) calcd for $\mathrm{C}_{22} \mathrm{H}_{20} \mathrm{BrN}_{2} \mathrm{O}_{5}{ }^{+}[\mathrm{M}+\mathrm{H}]^{+}:$: 471.0550, found: 471.0547 .

Step 2: To a stirred solution of compound 11 (1.000 g, $2.1 \mathrm{mmol}, 1.0$ equiv) in dry DMF (15 mL) were added $\mathrm{K}_{2} \mathrm{CO}_{3}(1.451 \mathrm{~g}, 10.5 \mathrm{mmol}, 5.0$ equiv) and compound $\mathbf{S 1}$ (4.940 g, $10.5 \mathrm{mmol}, 5.0$ equiv). The mixture was heated to $50{ }^{\circ} \mathrm{C}$. When the consumption of compound $\mathbf{1 1}$ completed, as monitored by TLC, the mixture was purified by silica gel flash column chromatography $(\mathrm{DCM} / \mathrm{MeOH})$ to afford compound $12(0.783 \mathrm{~g}, 43 \%$ yield $)$. Yellow soild, $\mathrm{mp}=144.3-146.7^{\circ} \mathrm{C} .{ }^{1} \mathbf{H}$ $\operatorname{NMR}\left(500 \mathrm{MHz}, \mathrm{CDCl}_{3}\right) \delta_{\mathrm{H}} 8.23(\mathrm{~s}, 1 \mathrm{H}), 8.08(\mathrm{~d}, J=9.3 \mathrm{~Hz}, 1 \mathrm{H}), 7.62(\mathrm{~s}, 1 \mathrm{H}), 7.53(\mathrm{~d}, J=0.6 \mathrm{~Hz}$, 1H), 7.49-7.43 (m, 1H), 7.23-7.27 (m, 1H), $6.43(\mathrm{dd}, J=7.9,5.8 \mathrm{~Hz}, 1 \mathrm{H}), 5.74(\mathrm{~d}, J=16.2 \mathrm{~Hz}, 1 \mathrm{H})$, $5.30(\mathrm{~d}, J=15.9 \mathrm{~Hz}, 1 \mathrm{H}), 5.25(\mathrm{~s}, 2 \mathrm{H}), 4.53-4.47(\mathrm{~m}, 2 \mathrm{H}), 4.45-4.42(\mathrm{~m}, 1 \mathrm{H}), 4.41-4.33(\mathrm{~m}, 2 \mathrm{H})$, 4.03-3.95 (m, 2H), $3.89(\mathrm{dd}, J=11.4,2.4 \mathrm{~Hz}, 1 \mathrm{H}), 3.79(\mathrm{dd}, J=11.4,2.2 \mathrm{~Hz}, 1 \mathrm{H}), 2.33-2.26(\mathrm{~m}$, 1H), 2.08-2.00 (s, 1H), 1.98 (s, 3H), 1.96-1.86 (m, 2H), 1.04 (t, $J=7.4 \mathrm{~Hz}, 3 \mathrm{H}), 0.94$ (s, 9H), 0.92 (s, 9H), $0.13(\mathrm{~d}, J=1.4 \mathrm{~Hz}, 6 \mathrm{H}), 0.11(\mathrm{~s}, 3 \mathrm{H}), 0.10(\mathrm{~s}, 3 \mathrm{H}) ;{ }^{13} \mathbf{C}$ NMR $\left(126 \mathrm{MHz}, \mathrm{CDCl}_{3}\right) \delta_{\mathrm{C}} 174.0$, $163.5,157.8,157.7,151.0,150.2,150.1,146.7,145.1,133.9,131.1,129.6,129.5,129.0,123.9$, $117.9,110.1,106.4,97.5,87.9,85.5,72.8,72.3,66.3,64.6,63.0,50.1,41.5,39.7,31.6,25.9,25.8$, 18.4, 18.0, 13.3, 7.9, -4.6, -4.8, -5.4, -5.5; IR: $\bar{v}=3434,2930,1705,1660,1466,1238,1109,836$, 778; HRMS m/z (ESI) calcd for $\mathrm{C}_{44} \mathrm{H}_{61} \mathrm{~N}_{4} \mathrm{O}_{10} \mathrm{Si}_{2}{ }^{+}[\mathrm{M}+\mathrm{H}]^{+}:$: 861.3921, found: 861.3917.

Step 3 : To a stirred solution of compound $12(0.600 \mathrm{~g}, 0.7 \mathrm{mmol}, 1.0$ equiv) in EtOH was added $10 \% \mathrm{HCl}$ aq. The reaction mixture was stirred overnight at ambient temperature. When the consumption of compound $\mathbf{1 2}$ completed, as monitored by TLC, the mixture was purified by silica gel flash column chromatography (DCM/MeOH) to afford compound 3 (0.390 g, 89\% yield). Yellow soild, mp $=198.8-201.2^{\circ} \mathrm{C} .{ }^{1} \mathbf{H}$ NMR $(500 \mathrm{MHz}, \mathrm{DMSO}) \delta_{\mathrm{H}} 8.48(\mathrm{~s}, 1 \mathrm{H}), 8.04(\mathrm{~d}, J=9.2$ $\mathrm{Hz}, 1 \mathrm{H}), 7.84(\mathrm{~s}, 1 \mathrm{H}), 7.56(\mathrm{t}, J=2.7 \mathrm{~Hz}, 1 \mathrm{H}), 7.49-7.41(\mathrm{~m}, 1 \mathrm{H}), 7.27(\mathrm{~s}, 1 \mathrm{H}), 6.26-6.13(\mathrm{~m}, 1 \mathrm{H})$, $5.41(\mathrm{~s}, 2 \mathrm{H}), 5.23(\mathrm{~s}, 2 \mathrm{H}), 4.40-4.16(\mathrm{~m}, 6 \mathrm{H}), 3.64-3.52(\mathrm{~m}, 1 \mathrm{H}), 3.40(\mathrm{~d}, J=4.7 \mathrm{~Hz}, 1 \mathrm{H}), 2.11(\mathrm{dd}$, $J=6.6,4.8 \mathrm{~Hz}, 1 \mathrm{H}), 2.02-1.67(\mathrm{~m}, 6 \mathrm{H}), 0.88(\mathrm{t}, J=7.3 \mathrm{~Hz}, 3 \mathrm{H}) ;{ }^{13} \mathbf{C}$ NMR $(126 \mathrm{MHz}, \mathrm{DMSO}) \delta_{\mathrm{C}}$ 
173.0, 163.3, 157.4, 157.3, 151.0, 150.7, 150.5, 146.1, 144.4, 130.9, 130.7, 130.5, 129.8, 123.5, $118.9,107.5,96.6,89.7,87.9,86.9,85.4,72.9,70.7,65.7,65.0,62.1,61.6,50.7,34.5,30.7,13.4$, 8.3; IR: $\bar{v}=3404,1744,1656,1623,1469,1247,1047,771 ;$ HRMS m/z (ESI) calcd for $\mathrm{C}_{32} \mathrm{H}_{33} \mathrm{~N}_{4} \mathrm{O}_{10}+[\mathrm{M}+\mathrm{H}]^{+}:$633.2191, found: 633.2196 .

Scheme S4. Synthesis of compound 8

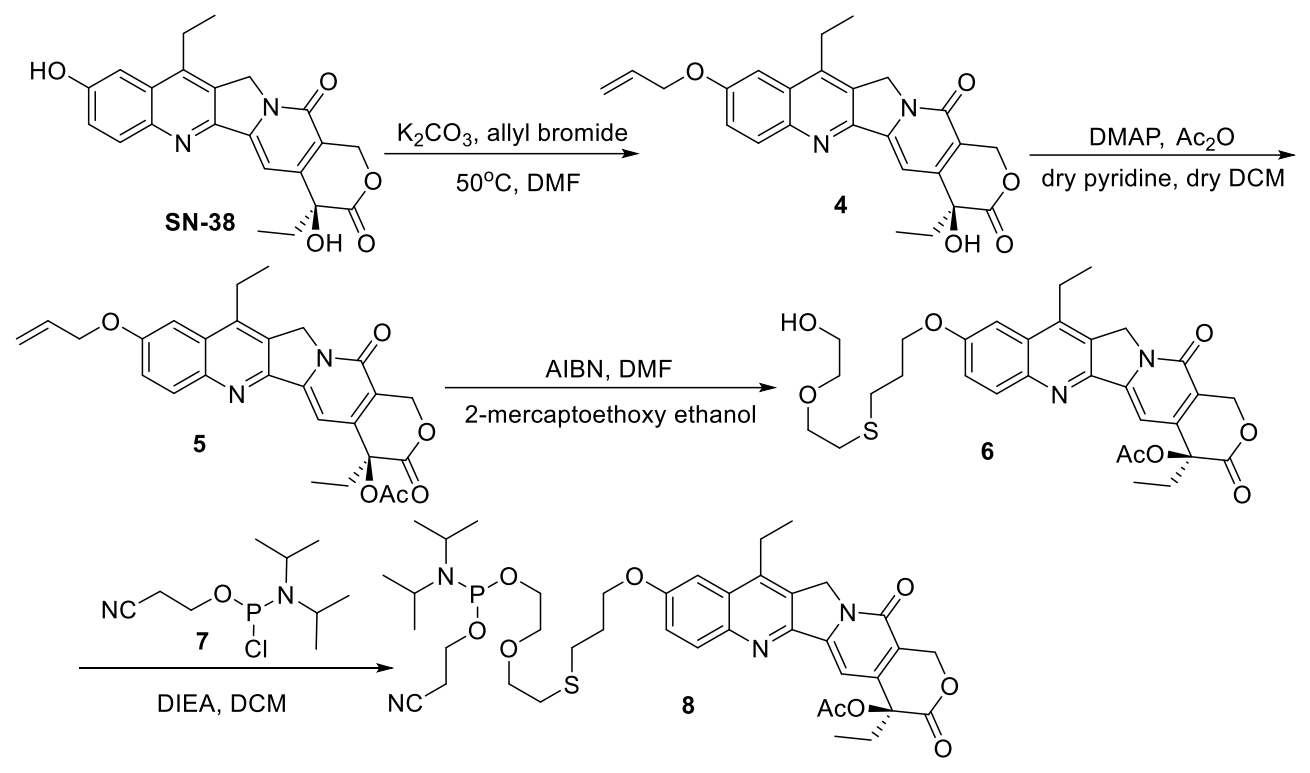

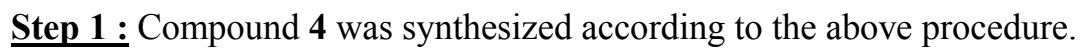

Step 2: To a stirred solution of compound 4 (1.000 g, $2.3 \mathrm{mmol}, 1.0$ equiv) in dry DCM (35 mL) were added $\mathrm{Ac}_{2} \mathrm{O}$ ( $0.587 \mathrm{~g}, 5.75 \mathrm{mmol}, 2.5$ equiv), DMAP (28 mg, $0.23 \mathrm{mmol}, 0.1$ equiv) and dry pyridine $(8.0 \mathrm{~mL})$. The reaction mixture was stirred overnight at ambient temperature. Upon full consumption of compound 4 , the reaction mixture was poured into water, eluting with DCM ( $3 \mathrm{x})$. The combined organic phases were dried over $\mathrm{Na}_{2} \mathrm{SO}_{4}$ and concentrated in vacuo. The residue was purified by silica gel flash column chromatography (DCM/MeOH) to afford compound 5 (0.985 g, $90 \%$ yield). Yellow soild, $\mathrm{mp}=275.4-278.2{ }^{\circ} \mathrm{C} .{ }^{1} \mathbf{H}$ NMR $\left(500 \mathrm{MHz}, \mathrm{CDCl}_{3}\right) \delta_{\mathrm{H}} 8.13(\mathrm{~d}, J=9.3$ $\mathrm{Hz}, 1 \mathrm{H}), 7.51(\mathrm{dd}, J=9.3,2.7 \mathrm{~Hz}, 1 \mathrm{H}), 7.36(\mathrm{~d}, J=2.7 \mathrm{~Hz}, 1 \mathrm{H}), 7.16(\mathrm{~s}, 1 \mathrm{H}), 6.21-6.09(\mathrm{~m}, 1 \mathrm{H})$, $5.68(\mathrm{~d}, J=17.0 \mathrm{~Hz}, 1 \mathrm{H}), 5.53(\mathrm{dd}, J=17.3,1.4 \mathrm{~Hz}, 1 \mathrm{H}), 5.44-5.38(\mathrm{~m}, 2 \mathrm{H}), 5.22(\mathrm{~d}, J=3.4 \mathrm{~Hz}$ 2H), $4.75(\mathrm{dd}, J=4.0,1.3 \mathrm{~Hz}, 2 \mathrm{H}), 3.14(\mathrm{q}, J=7.7 \mathrm{~Hz}, 2 \mathrm{H}), 2.32-2.24(\mathrm{~m}, 1 \mathrm{H}), 2.21$ (s, 3H), 2.19$2.11(\mathrm{~m}, 1 \mathrm{H}), 1.39(\mathrm{t}, J=7.7 \mathrm{~Hz}, 3 \mathrm{H}), 0.98(\mathrm{t}, J=7.5 \mathrm{~Hz}, 3 \mathrm{H}) ;{ }^{13} \mathbf{C} \mathbf{~ N M R}\left(126 \mathrm{MHz}, \mathrm{CDCl}_{3}\right) \delta_{\mathrm{C}}$ $169.8,167.7,157.8,157.4,149.6,147.1,145.9,145.3,143.9,132.6,131.8,128.2,127.2,122.8$, 119.5, 118.4, 103.1, 95.3, 75.9, 69.3, 67.1, 49.3, 31.8, 23.2, 20.8, 13.6, 7.6; IR: $\bar{v}=3452,2939$, 
1747, 1663, 1603, 1515, 1233, 1155, 824; HRMS m/z (ESI) calcd for $\mathrm{C}_{27} \mathrm{H}_{27} \mathrm{~N}_{2} \mathrm{O}_{6}{ }^{+}[\mathrm{M}+\mathrm{H}]^{+}$: 475.1864, found: 475.1862 .

Step 3: To a stirred solution of compound $5(0.900 \mathrm{~g}, 1.9 \mathrm{mmol}, 1.0$ equiv) in dry DMF (15 mL) were added AIBN (0.156 g, 0.95 mmol, 0.5 equiv) and 2-mercaptoethoxy ethanol (1.160 g, 9.5 mmol, 5.0 equiv). The reaction mixture was heated to $80{ }^{\circ} \mathrm{C}$ under $\mathrm{N}_{2}$ atmosphere. Upon full consumption of compound $\mathbf{5}$, the reaction mixture was poured into water, eluting with EtOAc ( $3 \mathrm{x})$. The combined organic phases were dried over $\mathrm{Na}_{2} \mathrm{SO}_{4}$ and concentrated in vacuo. The residue was purified by silica gel flash column chromatography $(\mathrm{DCM} / \mathrm{MeOH})$ to afford compound $6(0.675 \mathrm{~g}$, $60 \%$ yield). Yellow oil. ${ }^{1} \mathrm{H}$ NMR $\left(500 \mathrm{MHz}, \mathrm{CDCl}_{3}\right) \delta_{\mathrm{H}} 7.98(\mathrm{~d}, J=9.2 \mathrm{~Hz}, 1 \mathrm{H}), 7.35(\mathrm{dd}, J=9.2$, $2.5 \mathrm{~Hz}, 1 \mathrm{H}), 7.19(\mathrm{~d}, J=2.5 \mathrm{~Hz}, 1 \mathrm{H}), 7.06(\mathrm{~s}, 1 \mathrm{H}), 5.55(\mathrm{~d}, J=16.9 \mathrm{~Hz}, 1 \mathrm{H}), 5.29(\mathrm{~d}, J=16.9 \mathrm{~Hz}$, $1 \mathrm{H}), 5.03(\mathrm{~d}, J=3.5 \mathrm{~Hz}, 2 \mathrm{H}), 4.14(\mathrm{t}, J=6.0 \mathrm{~Hz}, 2 \mathrm{H}), 3.68-3.64(\mathrm{~m}, 2 \mathrm{H}), 3.60(\mathrm{t}, J=6.6 \mathrm{~Hz}, 2 \mathrm{H})$, 3.52-3.48 (m, 2H), 2.99 (dd, $J=15.1,7.4 \mathrm{~Hz}, 2 \mathrm{H}), 2.73(\mathrm{t}, J=7.1 \mathrm{~Hz}, 2 \mathrm{H}), 2.67(\mathrm{t}, J=6.6 \mathrm{~Hz}, 2 \mathrm{H})$, 2.19-2.11 (m, 4H), 2.10-2.00 (m, 3H), 1.27 (t, $J=7.7 \mathrm{~Hz}, 3 \mathrm{H}), 0.89(\mathrm{t}, J=7.5 \mathrm{~Hz}, 3 \mathrm{H}) ;{ }^{13} \mathbf{C}$ NMR $\left(126 \mathrm{MHz}, \mathrm{CDCl}_{3}\right) \delta_{\mathrm{C}} 169.8,167.6,158.0,157.3,149.2,147.0,146.0,145.0,143.8,131.6,128.1$, $127.1,122.7,119.1,102.5,95.3,75.9,72.2,70.5,66.9,66.6,61.5,49.2,31.6,31.5,29.1,28.9,23.0$, 20.7, 13.6, 7.6; IR: $\bar{v}=3445,2923,1747,1661,1611,1234,1057,831,744 ;$ HRMS m/z (ESI) calcd for $\mathrm{C}_{31} \mathrm{H}_{37} \mathrm{~N}_{2} \mathrm{O}_{8} \mathrm{~S}^{+}[\mathrm{M}+\mathrm{H}]^{+}:$597.2265, found: 597.2263.

Step 4 : To a stirred solution of compound $6(0.600 \mathrm{~g}, 1.0 \mathrm{mmol}, 1.0$ equiv $)$ and DIEA $(0.388 \mathrm{~g}, 3.0$ mmol, 3.0 equiv) in dry DCM $(15 \mathrm{~mL})$ at $0{ }^{\circ} \mathrm{C}$ was added $N$-diisopropylchlorophosphoramidite 7 ( $0.284 \mathrm{~g}, 1.2 \mathrm{mmol}, 1.2$ equiv) dropwise. Upon full consumption of compound $\mathbf{6}$, the reaction mixture was diluted with DCM $(40 \mathrm{~mL})$ and washed with saturated sodium bicarbonate and saturated saline. After drying with $\mathrm{Na}_{2} \mathrm{SO}_{4}$, the solution was concentrated, and the residue was purified by silica gel flash column chromatography (DCM/MeOH) to afford compound $8(0.446 \mathrm{~g}$, $56 \%$ yield). Yellow oil. ${ }^{1} \mathrm{H}$ NMR $\left(500 \mathrm{MHz}, \mathrm{CDCl}_{3}\right) \delta_{\mathrm{H}} 8.13(\mathrm{~d}, J=9.2 \mathrm{~Hz}, 1 \mathrm{H}), 7.49(\mathrm{dd}, J=9.2$, $2.6 \mathrm{~Hz}, 1 \mathrm{H}), 7.36(\mathrm{~d}, J=2.4 \mathrm{~Hz}, 1 \mathrm{H}), 7.16(\mathrm{~s}, 1 \mathrm{H}), 5.69(\mathrm{~d}, J=17.0 \mathrm{~Hz}, 1 \mathrm{H}), 5.42(\mathrm{~d}, J=17.0 \mathrm{~Hz}$, $1 \mathrm{H}), 5.24(\mathrm{~d}, J=2.6 \mathrm{~Hz}, 2 \mathrm{H}), 4.28(\mathrm{t}, J=6.0 \mathrm{~Hz}, 2 \mathrm{H}), 4.25-4.12(\mathrm{~m}, 1 \mathrm{H}), 3.94-3.81(\mathrm{~m}, 3 \mathrm{H}), 3.78-$ $3.70(\mathrm{~m}, 3 \mathrm{H}), 3.68-3.49(\mathrm{~m}, 5 \mathrm{H}), 2.86(\mathrm{t}, J=7.0 \mathrm{~Hz}, 2 \mathrm{H}), 2.79(\mathrm{t}, J=5.0 \mathrm{~Hz}, 2 \mathrm{H}), 2.66(\mathrm{t}, J=6.5$ $\mathrm{Hz}, 2 \mathrm{H}), 2.34-2.26(\mathrm{~m}, 1 \mathrm{H}), 2.24-2.12(\mathrm{~m}, 6 \mathrm{H}), 1.42(\mathrm{t}, J=7.7 \mathrm{~Hz}, 3 \mathrm{H}), 1.20(\mathrm{dd}, J=6.8,2.3 \mathrm{~Hz}$ 12H), 0.99 (t, $J=7.5 \mathrm{~Hz}, 3 \mathrm{H}) ;{ }^{31} \mathbf{P}$ NMR $\left(202 \mathrm{MHz}, \mathrm{CDCl}_{3}\right) \delta_{\mathrm{P}} 148.7 ; \mathbf{H R M S ~ m / z ~ ( E S I ) ~ c a l c d ~ f o r ~}$ $\mathrm{C}_{40} \mathrm{H}_{54} \mathrm{~N}_{4} \mathrm{O}_{9} \mathrm{PS}^{+}[\mathrm{M}+\mathrm{H}]^{+}:$797.3344, found: 797.3342 . 
Scheme S5. Synthesis of compound 10

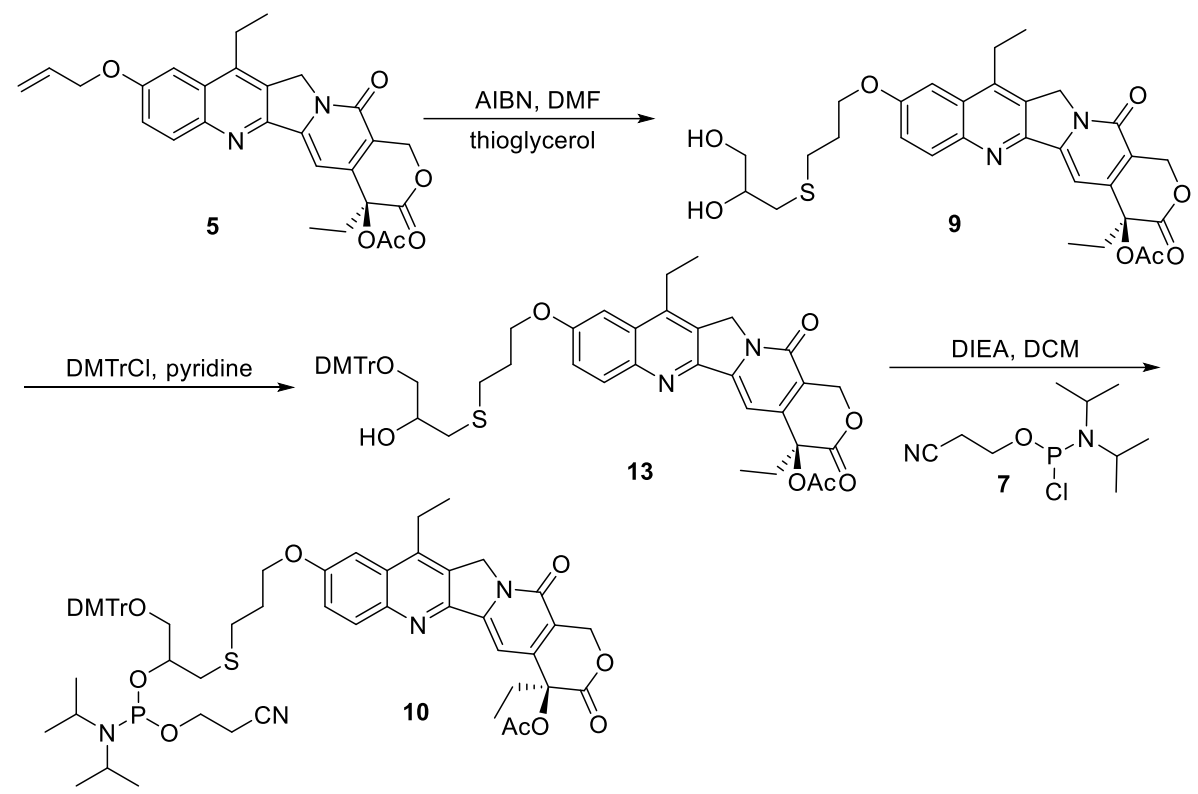

Compound 5 was synthesized according to the above procedure.

Step 1 : To a stirred solution of compound 5 ( $0.900 \mathrm{~g}, 1.9 \mathrm{mmol}, 1.0$ equiv) in dry DMF (15 mL) were added AIBN ( $0.156 \mathrm{~g}, 0.95 \mathrm{mmol}, 0.5$ equiv) and thioglycerol (1.03 g, $9.5 \mathrm{mmol}, 5.0$ equiv). The reaction mixture was heated to $80{ }^{\circ} \mathrm{C}$ under $\mathrm{N}_{2}$ atmosphere. Upon full consumption of compound $\mathbf{5}$, the reaction mixture was poured into water, eluting with EtOAc $(3 \mathrm{x})$. The combined organic phases were dried over $\mathrm{Na}_{2} \mathrm{SO}_{4}$ and concentrated in vacuo. The residue was purified by silica gel flash column chromatography (DCM/MeOH) to afford compound $9(0.700 \mathrm{~g}, 63 \%$ yield). Yellow oil. ${ }^{1} \mathrm{H}$ NMR $\left(500 \mathrm{MHz}, \mathrm{CDCl}_{3}\right) \delta_{\mathrm{H}} 8.13(\mathrm{~d}, J=9.3 \mathrm{~Hz}, 1 \mathrm{H}), 7.48(\mathrm{dd}, J=9.3,2.7 \mathrm{~Hz}, 1 \mathrm{H})$, $7.34(\mathrm{~d}, J=2.7 \mathrm{~Hz}, 1 \mathrm{H}), 7.17(\mathrm{~s}, 1 \mathrm{H}), 5.69(\mathrm{~d}, J=17.0 \mathrm{~Hz}, 1 \mathrm{H}), 5.42(\mathrm{~d}, J=17.0 \mathrm{~Hz}, 1 \mathrm{H}), 5.23(\mathrm{~d}$, $J=3.1 \mathrm{~Hz}, 2 \mathrm{H}), 4.28(\mathrm{t}, J=6.0 \mathrm{~Hz}, 2 \mathrm{H}), 3.92-3.83(\mathrm{~m}, 1 \mathrm{H}), 3.82-3.75(\mathrm{~m}, 1 \mathrm{H}), 3.65-3.55(\mathrm{~m}, 1 \mathrm{H})$, $3.16(\mathrm{q}, J=7.6 \mathrm{~Hz}, 2 \mathrm{H}), 2.86(\mathrm{t}, J=7.1 \mathrm{~Hz}, 2 \mathrm{H}), 2.79(\mathrm{dd}, J=13.7,4.6 \mathrm{~Hz}, 1 \mathrm{H}), 2.69(\mathrm{dd}, J=13.7$, $8.2 \mathrm{~Hz}, 1 \mathrm{H}), 2.34-2.24(\mathrm{~m}, 2 \mathrm{H}), 2.23(\mathrm{~s}, 3 \mathrm{H}), 2.21-2.13(\mathrm{~m}, 2 \mathrm{H}), 1.41(\mathrm{t}, J=7.7 \mathrm{~Hz}, 3 \mathrm{H}), 0.98(\mathrm{t}, J$ $=7.5 \mathrm{~Hz}, 3 \mathrm{H}) ;{ }^{13} \mathbf{C}$ NMR $\left(126 \mathrm{MHz}, \mathrm{CDCl}_{3}\right) \delta_{\mathrm{C}} 169.9,167.7,158.1,157.5,149.6,147.1,146.0$, $145.4,143.9,131.9,128.3,127.2,122.7,119.5,102.6,95.4,75.9,70.1,67.1,66.5,65.4,49.3,35.9$, 31.8, 29.2, 28.9, 23.1, 20.8, 13.6, 7.6; IR: $\bar{v}=3417,2931,1746,1660,1602,1233,1021,826,723$; HRMS m/z (ESI) calcd for $\mathrm{C}_{30} \mathrm{H}_{35} \mathrm{~N}_{2} \mathrm{O}_{8} \mathrm{~S}^{+}[\mathrm{M}+\mathrm{H}]^{+}:$583.2109, found: 583.2107.

Step 2: To a stirred solution of compound $9(0.700 \mathrm{~g}, 1.2 \mathrm{mmol}, 1.0 \mathrm{eq})$ in anhydrous pyridine (10 $\mathrm{mL}$ ) was added DMTrCl (0.610 g, $1.8 \mathrm{mmol}, 1.5$ equiv). Upon full consumption of compound $\mathbf{9}$, the reaction mixture was concentrated in vacuo. The residue was purified by silica gel flash column 
chromatography (DCM/MeOH) to afford the compound 13 ( $0.826 \mathrm{~g}, 78 \%$ yield). Pale red soild, $\mathrm{mp}$ $=123.7-125.7{ }^{\circ} \mathrm{C} .{ }^{1} \mathbf{H}$ NMR $\left(500 \mathrm{MHz}, \mathrm{CDCl}_{3}\right) \delta_{\mathrm{H}} 8.12(\mathrm{~d}, J=9.3 \mathrm{~Hz}, 1 \mathrm{H}), 7.49-7.42(\mathrm{~m}, 3 \mathrm{H})$, 7.36-7.29 (m, 7H), 7.23 (t, $J=7.3 \mathrm{~Hz}, 2 \mathrm{H}), 7.17$ (s, 1H), 6.87-6.82 (m, 4H), 5.69 (d, $J=17.0 \mathrm{~Hz}$, 1H), $5.42(\mathrm{~d}, J=17.0 \mathrm{~Hz}, 1 \mathrm{H}), 5.24(\mathrm{~d}, J=3.2 \mathrm{~Hz}, 2 \mathrm{H}), 4.25(\mathrm{t}, J=6.0 \mathrm{~Hz}, 2 \mathrm{H}), 3.95-3.87(\mathrm{~m}, 1 \mathrm{H})$, $3.79(\mathrm{~s}, 6 \mathrm{H}), 3.29-3.22(\mathrm{~m}, 2 \mathrm{H}), 3.14$ (q, $J=7.6 \mathrm{~Hz}, 2 \mathrm{H}), 2.85-2.75$ (m, 3H), 2.69 (dd, $J=13.7,7.5$ $\mathrm{Hz}, 1 \mathrm{H}), 2.33-2.25(\mathrm{~m}, 1 \mathrm{H}), 2.23(\mathrm{~s}, 3 \mathrm{H}), 2.21-2.11(\mathrm{~m}, 3 \mathrm{H}), 1.39$ (t, $J=7.7 \mathrm{~Hz}, 3 \mathrm{H}), 0.99$ (t, $J=$ $7.5 \mathrm{~Hz}, 3 \mathrm{H}) ;{ }^{13} \mathbf{C}$ NMR $\left(126 \mathrm{MHz}, \mathrm{CDCl}_{3}\right) \delta_{\mathrm{C}} 169.9,167.7,158.5,158.1,157.5,149.6,147.1,145.9$, $145.4,144.7,143.9,135.9,135.8,131.9,130.0,128.3,128.1,127.9,127.2,126.9,122.7,119.5$, 113.2, 102.6, 95.3, 86.3, 75.9, 69.8, 67.1, 66.6, 66.1, 55.2, 49.3, 46.2, 36.4, 31.8, 29.2, 29.1, 23.1, 20.8, 13.6, 7.6; IR: $\bar{v}=3431,2963,1748,1662,1608,1509,1251,1091,1030,805 ;$ HRMS m/z (ESI) calcd for $\mathrm{C}_{51} \mathrm{H}_{53} \mathrm{~N}_{2} \mathrm{O}_{10} \mathrm{~S}^{+}[\mathrm{M}+\mathrm{H}]^{+}$: 885.3415, found: 885.3415.

Step 3: To a stirred solution of compound 13 ( $0.800 \mathrm{~g}, 0.9 \mathrm{mmol}, 1.0$ equiv) and DIEA ( $0.350 \mathrm{~g}$, $2.7 \mathrm{mmol}, 3.0$ equiv) in dry DCM $(10 \mathrm{~mL})$ at $0{ }^{\circ} \mathrm{C}$ was added $N$-diisopropylchlorophosphoramidite 7 (0.256 g, $1.08 \mathrm{mmol}, 1.2$ equiv) dropwise. Upon full consumption of compound $\mathbf{1 3}$, the reaction mixture was diluted with DCM $(40 \mathrm{~mL})$ and washed with saturated sodium bicarbonate and saturated saline. After drying with $\mathrm{Na}_{2} \mathrm{SO}_{4}$, the solution was concentrated, and the residue was purified by silica gel flash column chromatography $(\mathrm{DCM} / \mathrm{MeOH})$ to afford compound $\mathbf{1 0}(0.685$ g, 70\% yield). Yellow oil. ${ }^{1} \mathbf{H}$ NMR $\left(500 \mathrm{MHz}, \mathrm{CD}_{3} \mathrm{CN}\right) \delta_{\mathrm{H}} 8.01(\mathrm{~d}, J=10.0 \mathrm{~Hz}, 1 \mathrm{H}), 7.50-7.45(\mathrm{~m}$, 2H), 7.44-7.39 (m, 2H), 7.37-7.27 (m, 6H), 7.25-7.19 (m, 1H), $7.02(\mathrm{~s}, 1 \mathrm{H}), 6.85(\mathrm{t}, J=8.1 \mathrm{~Hz}, 4 \mathrm{H})$, $5.57(\mathrm{~d}, J=16.7 \mathrm{~Hz}, 1 \mathrm{H}), 5.38(\mathrm{~d}, J=16.7 \mathrm{~Hz}, 1 \mathrm{H}), 5.15(\mathrm{~d}, J=2.6 \mathrm{~Hz}, 2 \mathrm{H}), 4.26(\mathrm{q}, J=6.2 \mathrm{~Hz}$, 2H), 4.16-4.06 (m, 2H), 3.92-3.82 (m, 1H), 3.77-3.73 (m, 6H), 3.72-3.53 (m, 3H), 3.28-3.24 (m, $1 \mathrm{H}), 3.17-3.12(\mathrm{~m}, 2 \mathrm{H}), 2.95-2.70(\mathrm{~m}, 4 \mathrm{H}), 2.69-2.64(\mathrm{~m}, 1 \mathrm{H}), 2.52(\mathrm{t}, J=6.0 \mathrm{~Hz}, 1 \mathrm{H}), 2.21$ (d, $J=$ $1.1 \mathrm{~Hz}, 3 \mathrm{H}), 2.17-2.05(\mathrm{~m}, 4 \mathrm{H}), 1.33(\mathrm{t}, J=7.6 \mathrm{~Hz}, 3 \mathrm{H}), 1.22-1.14(\mathrm{~m}, 9 \mathrm{H}), 1.07(\mathrm{~d}, J=6.8 \mathrm{~Hz}$, 3H), 1.00 (t, $J=7.4 \mathrm{~Hz}, 3 \mathrm{H}) ;{ }^{31} \mathbf{P}$ NMR $\left(202 \mathrm{MHz}, \mathrm{CD}_{3} \mathrm{CN}\right) \delta_{\mathrm{P}} 148.6,148.2 ; \mathbf{H R M S ~ m / z ~ ( E S I ) ~}$ calcd for $\mathrm{C}_{60} \mathrm{H}_{70} \mathrm{~N}_{4} \mathrm{O}_{11} \mathrm{PS}^{+}[\mathrm{M}+\mathrm{H}]^{+}:$1085.4494, found:1085.4490.

\section{Cell Viability of Precursor 1, 2 and 3}



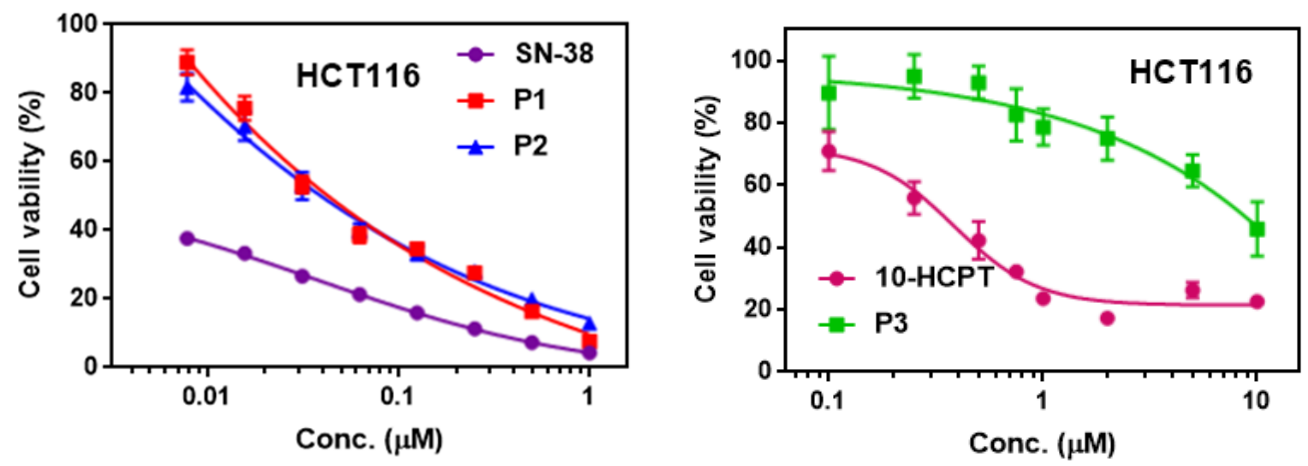

Figure S1. The cell viabilities of HCT116 cell line after 72 h treatment of 10-HCPT, SN-38, P1, P2 and $\mathbf{P 3}$

\section{ApDCs Synthesis and ESI-MS spectra of ApDCs}

Table S1. Detailed sequence data for SSC-1, SSC-2, SSC-3, sgc8 and Lib

\begin{tabular}{l|l}
\hline DNA & Sequence $^{\text {[a] }}$ \\
\hline SSC-1 & 5' (P1)TTTTTTATCTAACTGCTGCGCCGCCGGGAAAATACTGTACGGTTAGA-Cy5 3' \\
\hline SSC-2 & 5' (P2) TTTTTTATCTAACTGCTGCGCCGCCGGGAAAATACTGTACGGTTAGA-Cy5 3' \\
\hline SSC-3 & $\begin{array}{l}\text { 5' (P2)T(P2)T(P2)TTTTTTATCTAACTGCTGCGCCGCCGGGAAAATACTGTACGGTTAGA- } \\
\text { Cy5 3' }\end{array}$ \\
\hline sgc8 & 5' ATCTAACTGCTGCGCCGCCGGGAAAATACTGTACGGTTAGA-Cy5 3' \\
\hline Lib & 5' ATCTAACTGCNNNNNNNNNNNNNNNNNNNNTACGGTTAGA-Cy5 3' \\
\hline
\end{tabular}

[a] All DNA probes were synthesized by Sangon Biotech or TaKaRa Biotechnology (Dalian) CO., Ltd;

$\mathbf{P 1}$ presents the unit synthesized from phosphoramidite $\mathbf{8}$ and $\mathbf{P 2}$ from phosphoramidite $\mathbf{1 0}$.

ESI-MS calcd for SSC-1: 15609.69, found: 15606.7.

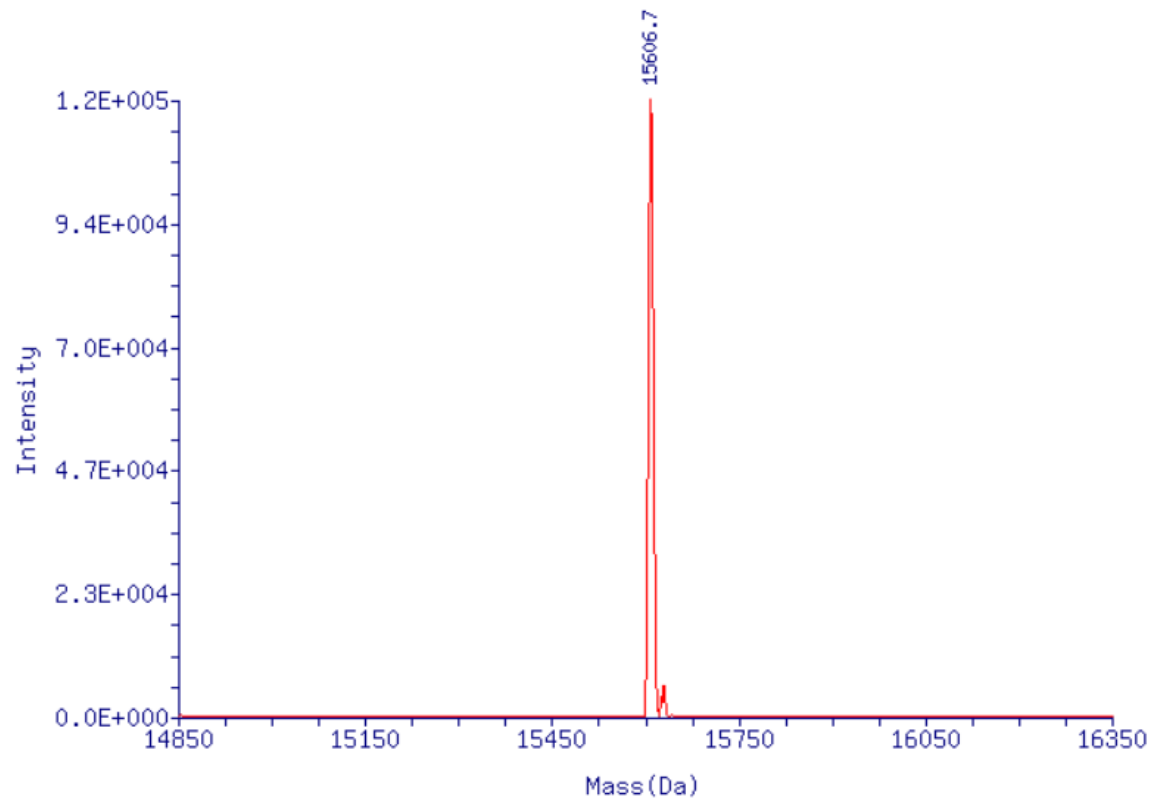


ESI-MS calcd for SSC-2: 15595.6, found: 15593.2.

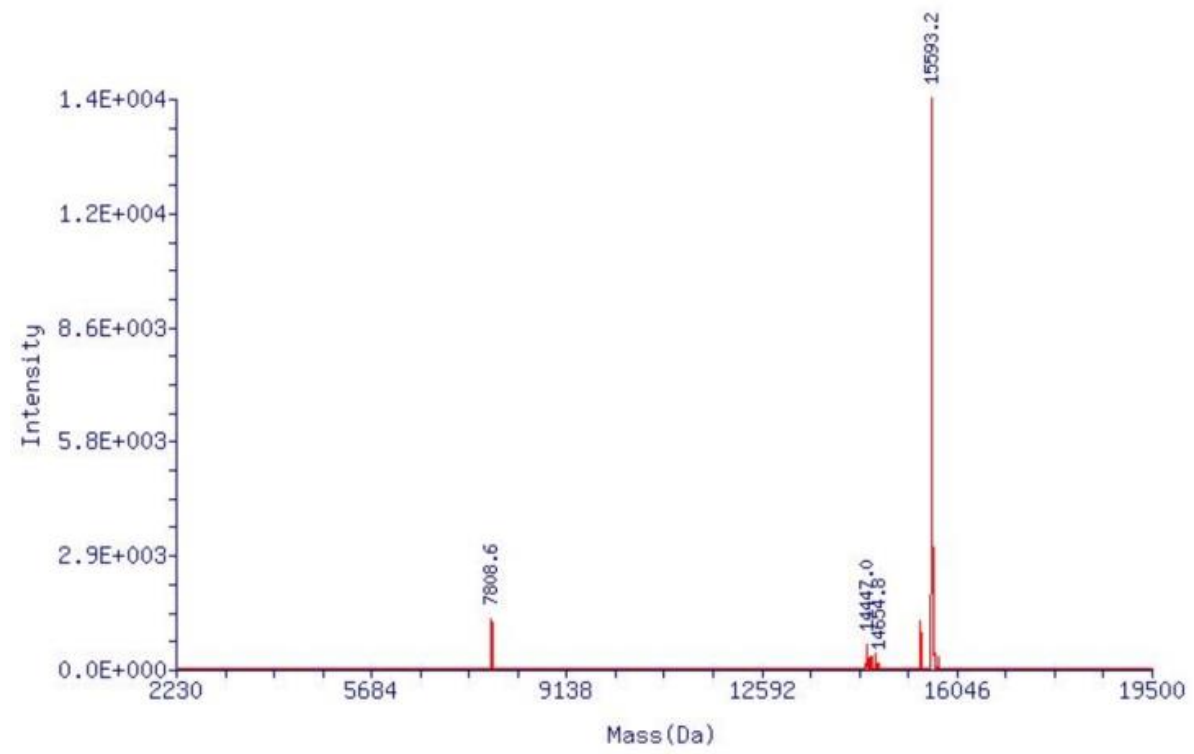

ESI-MS calcd for SSC-3: 17409.2, found: 17424.1.

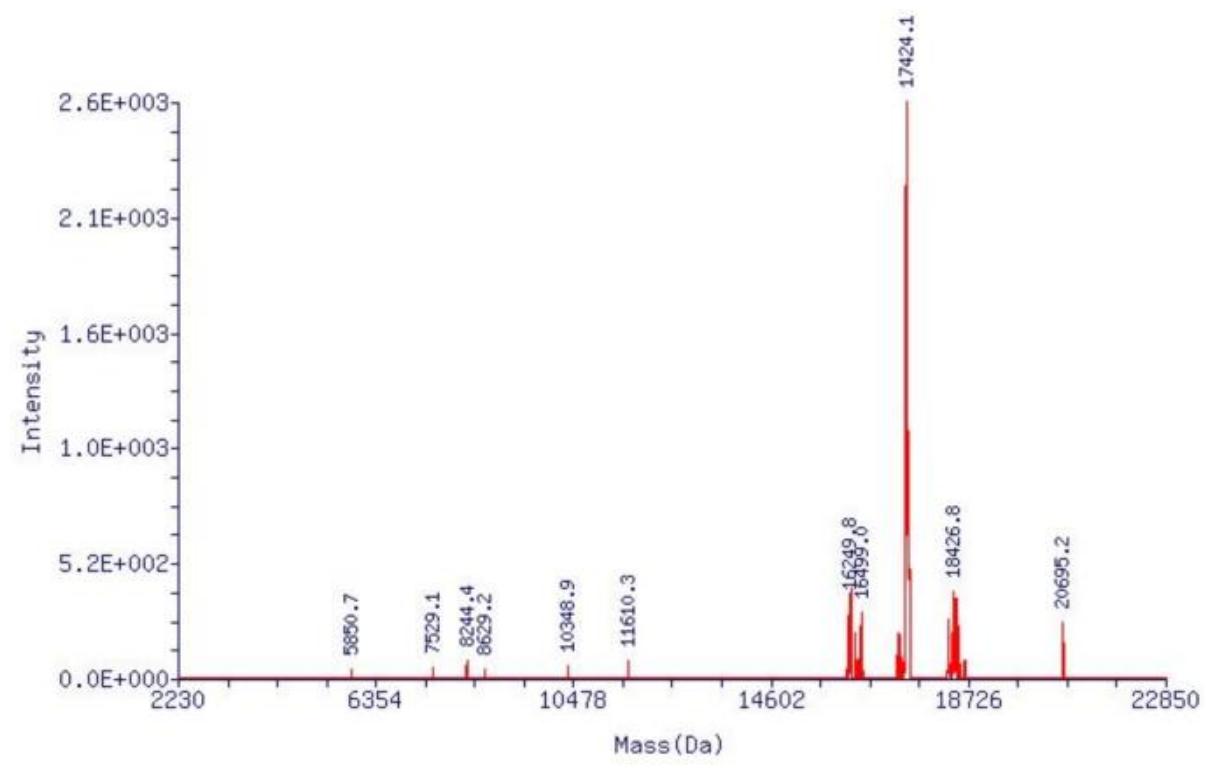

\section{Experiments on ApDCs Stability}

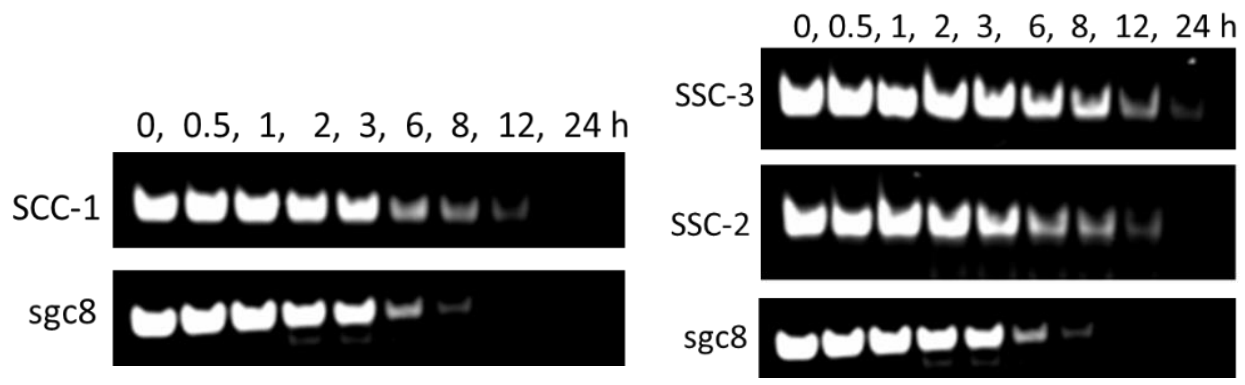

Figure S2. The stability of sgc8, SSC-1, SSC-2 and SSC-3 after treatment in RPMI-1640 medium supplemented with $10 \%$ fetal bovine serum (FBS); $\mathbf{s g c 8}$ as a control group. 


\section{Copies of NMR Spectra}

\section{Compound 1}
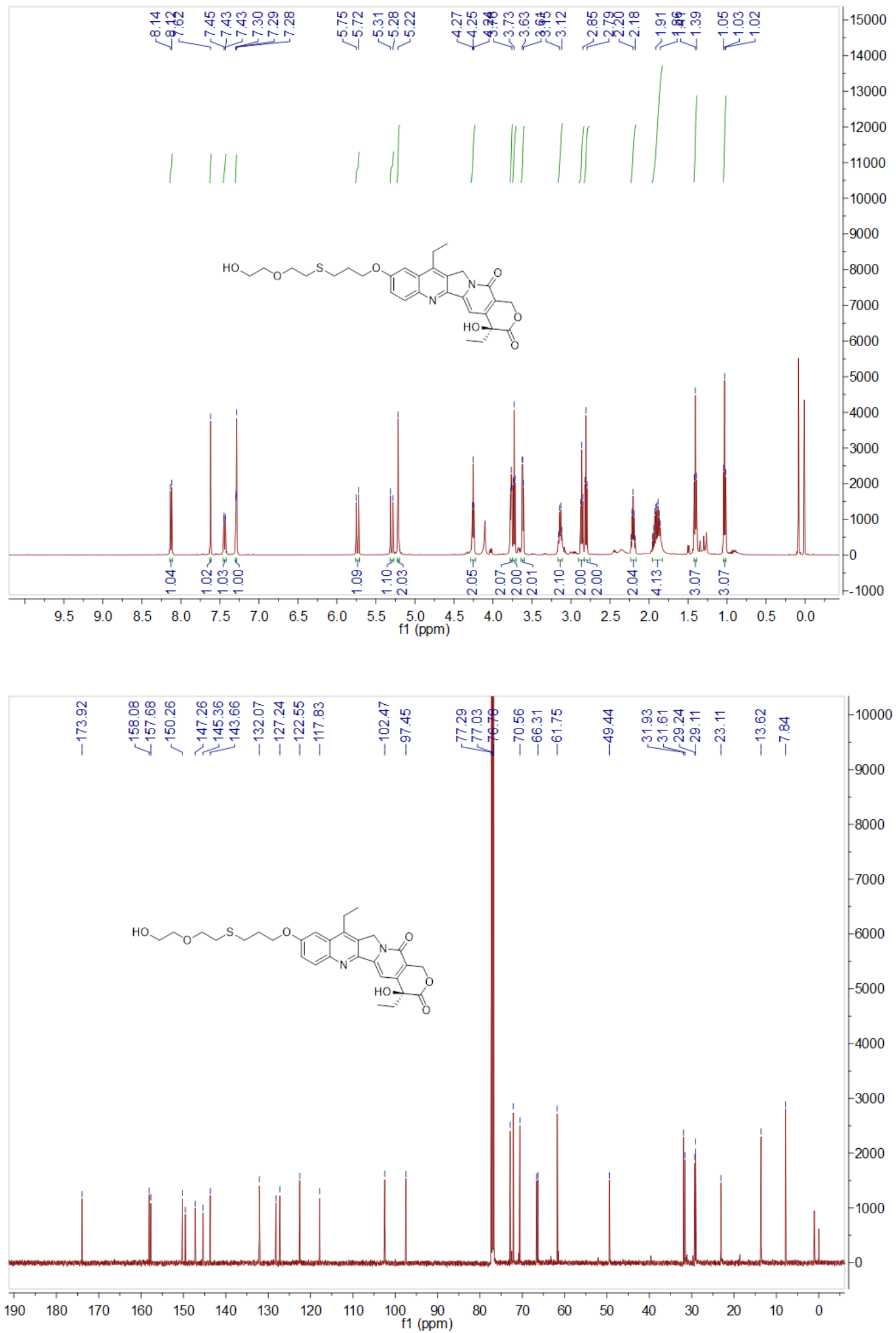


\section{Compound 2}
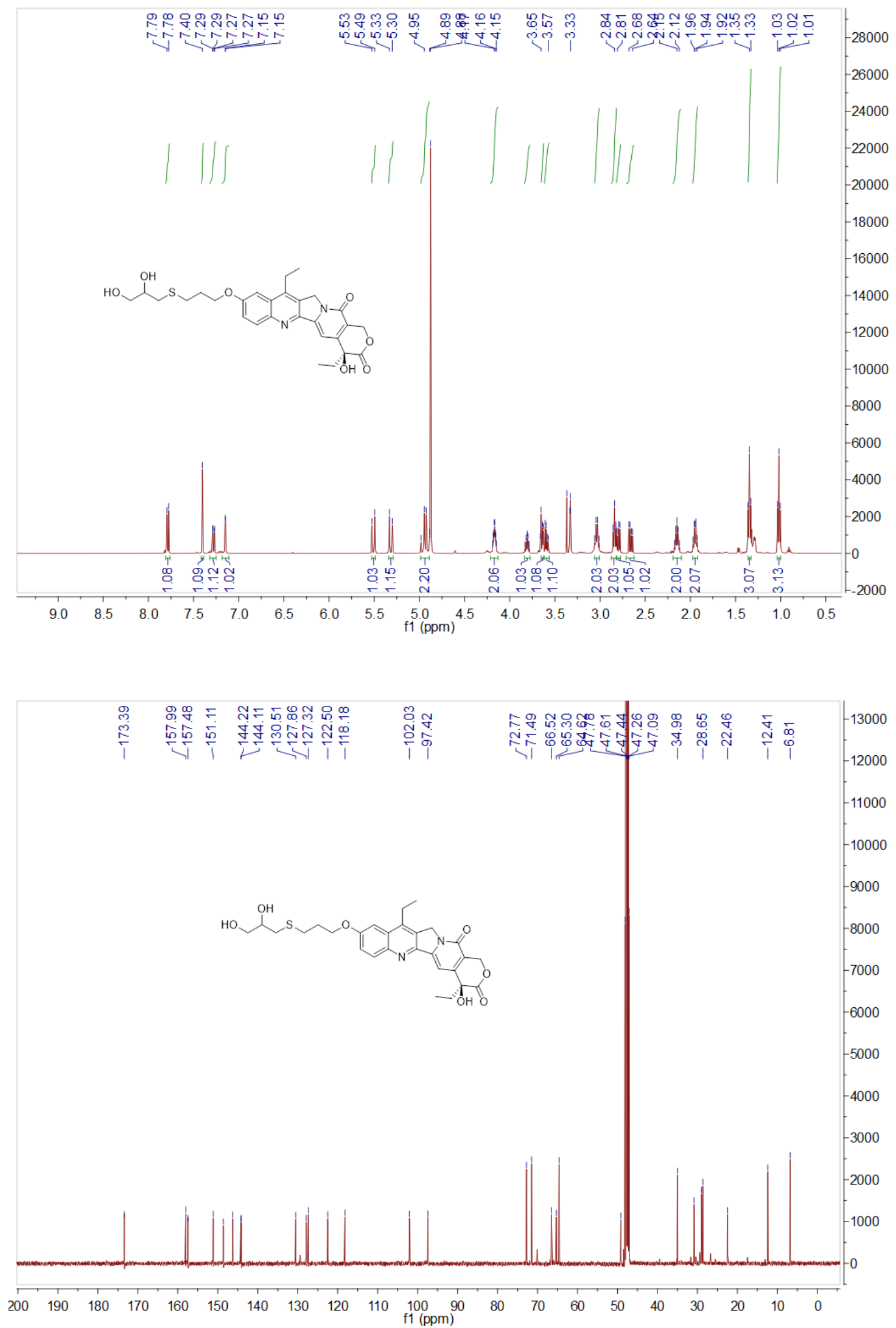


\section{Compound 3}
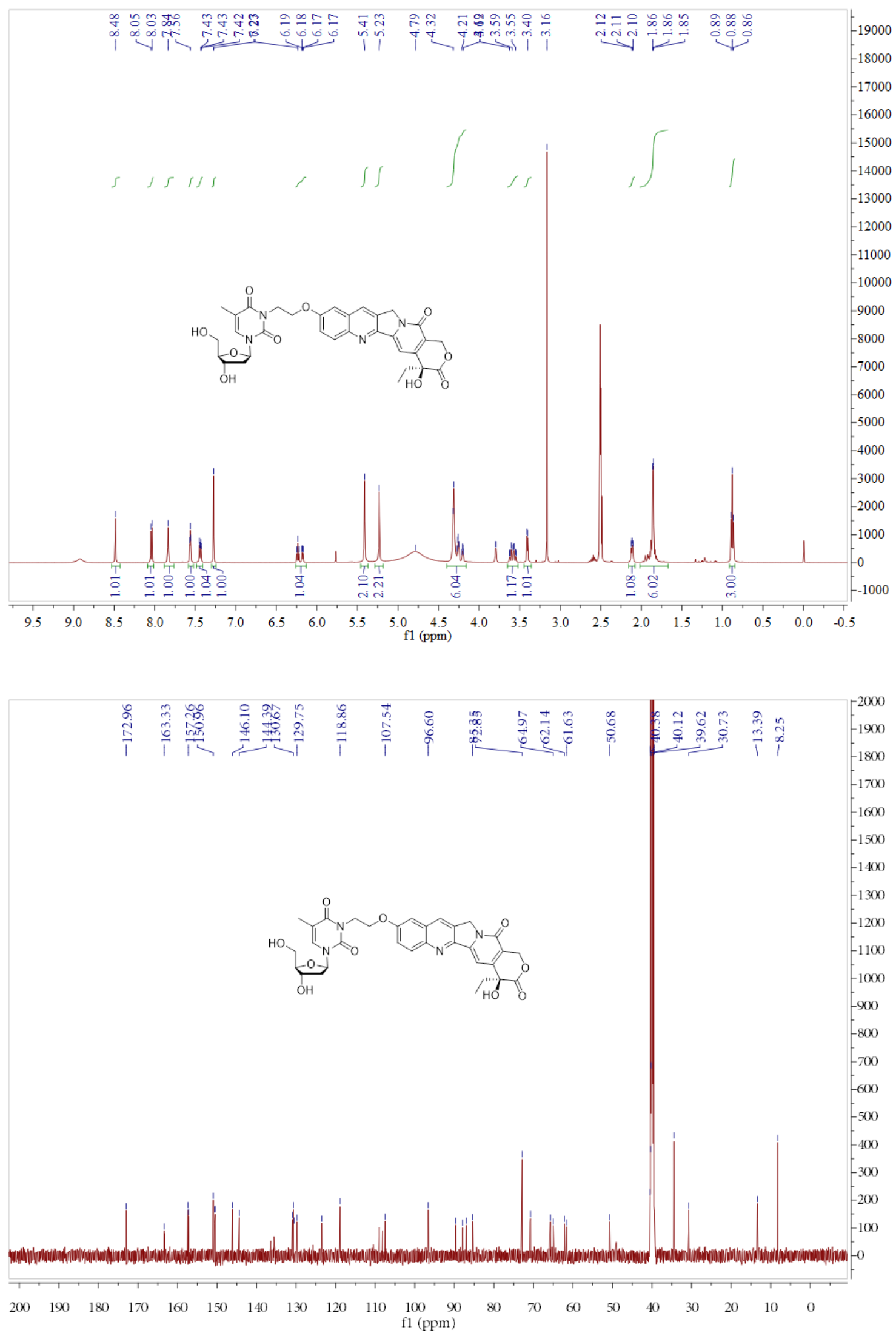


\section{Compound 4}
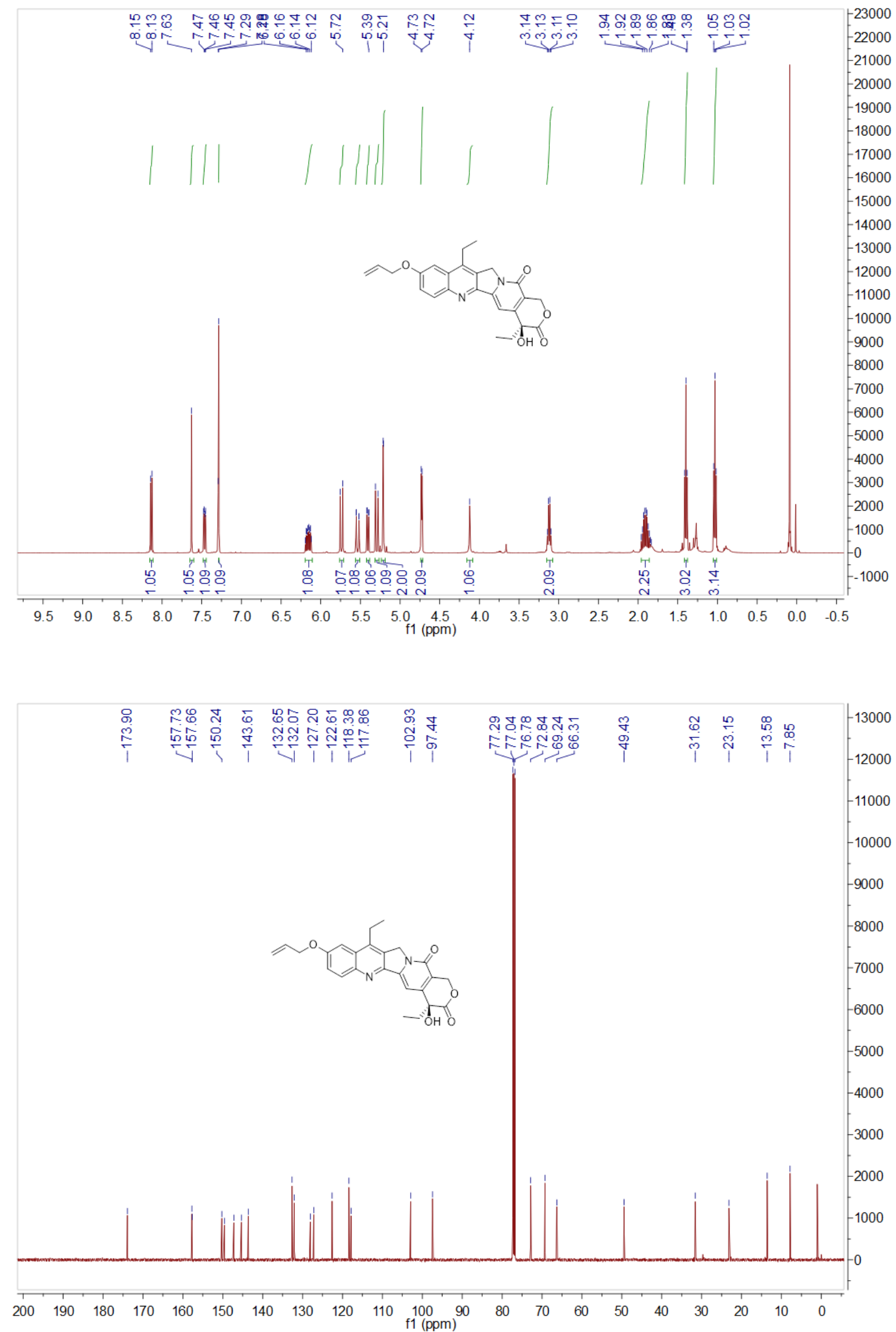


\section{Compound 5}
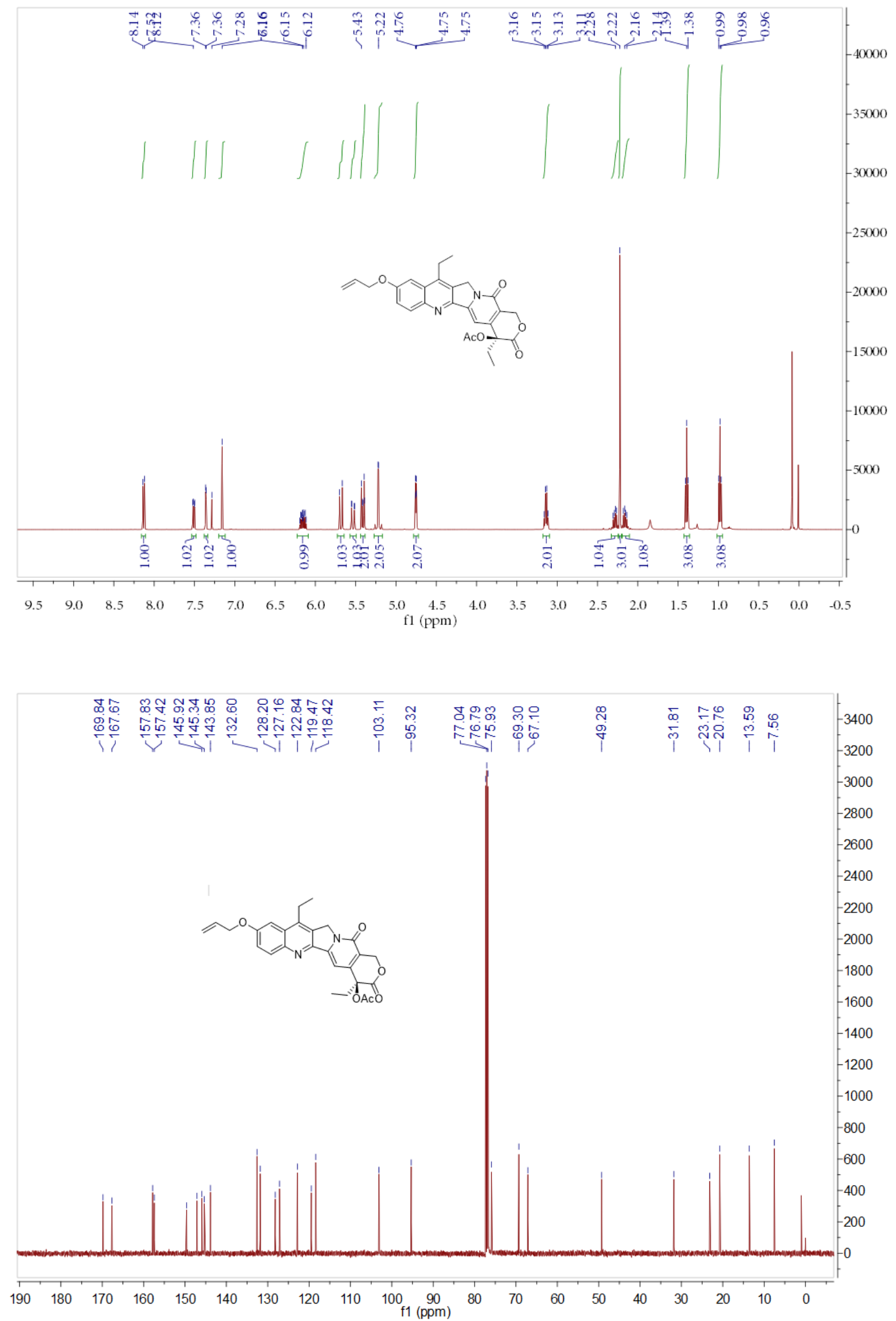


\section{Compound 6}
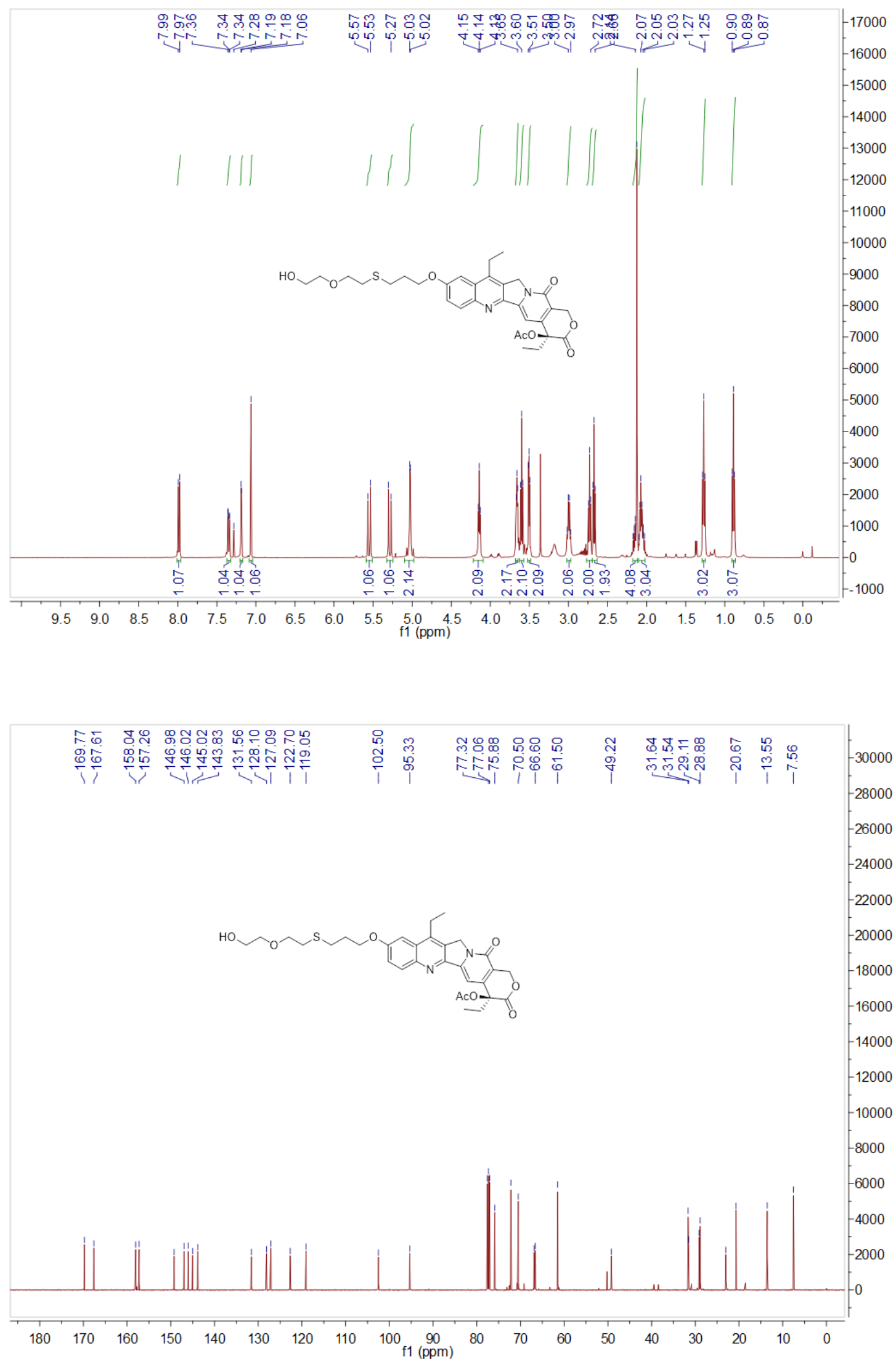


\section{Compound 8}
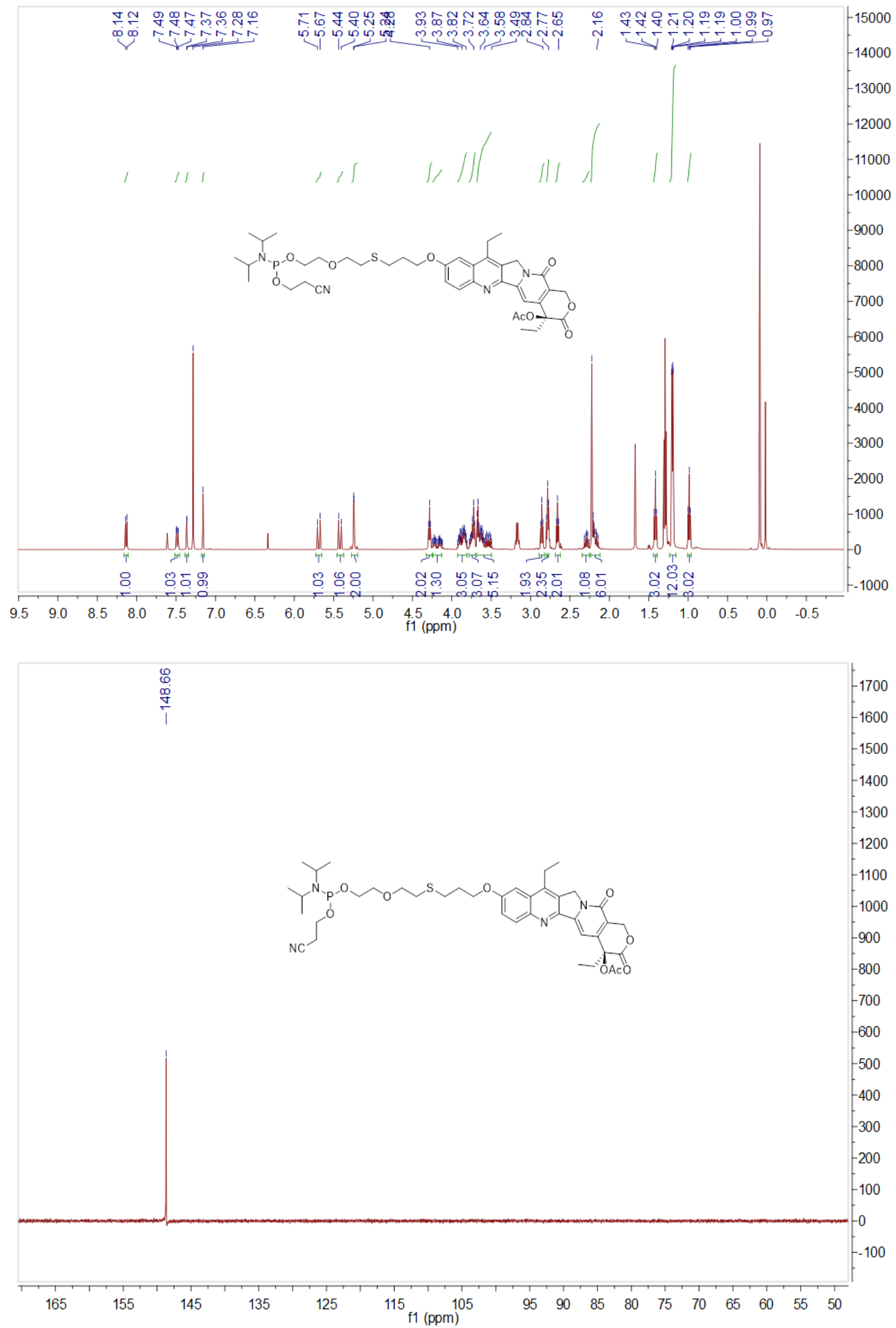


\section{Compound 9}
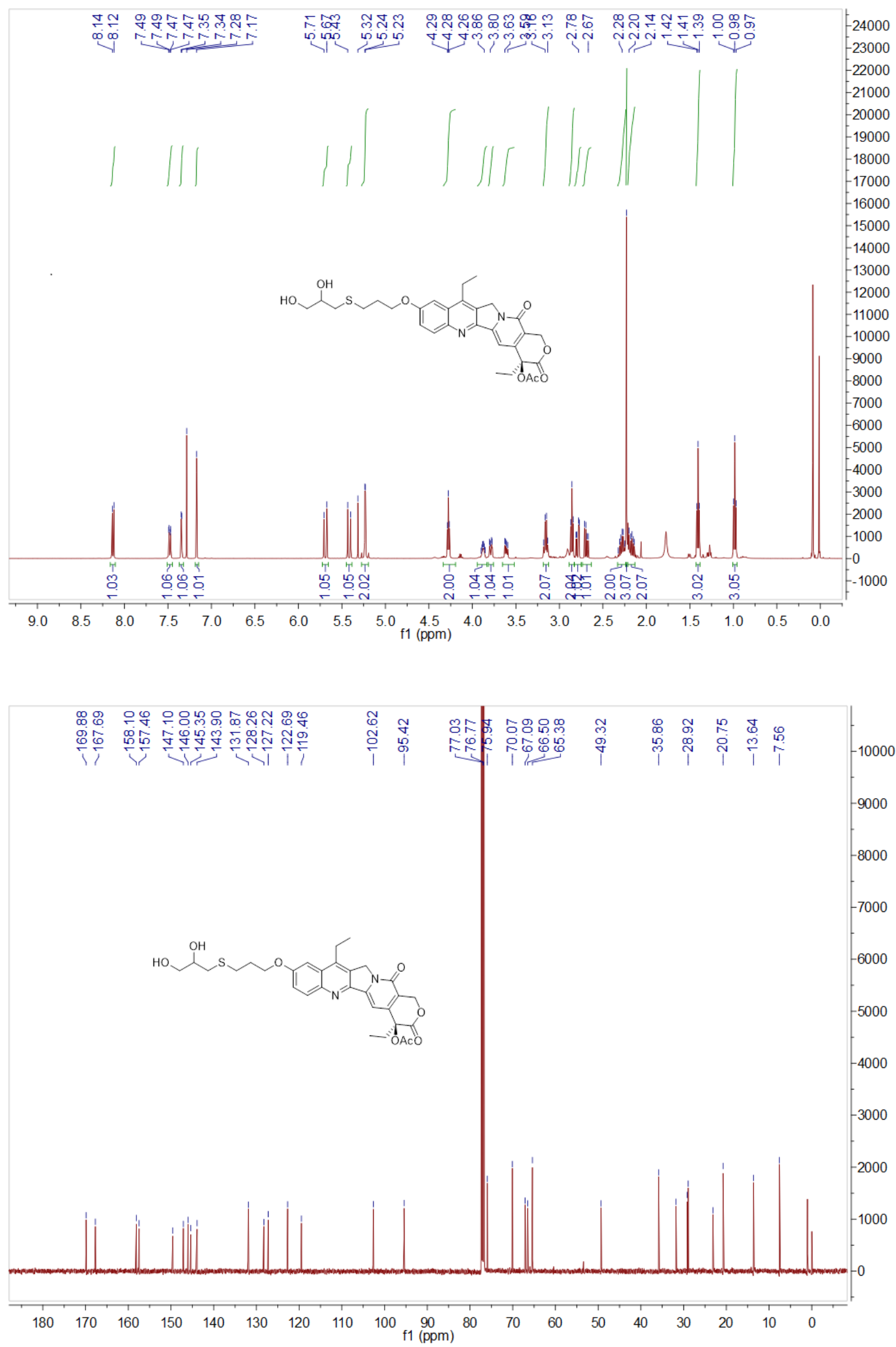


\section{Compound 10}
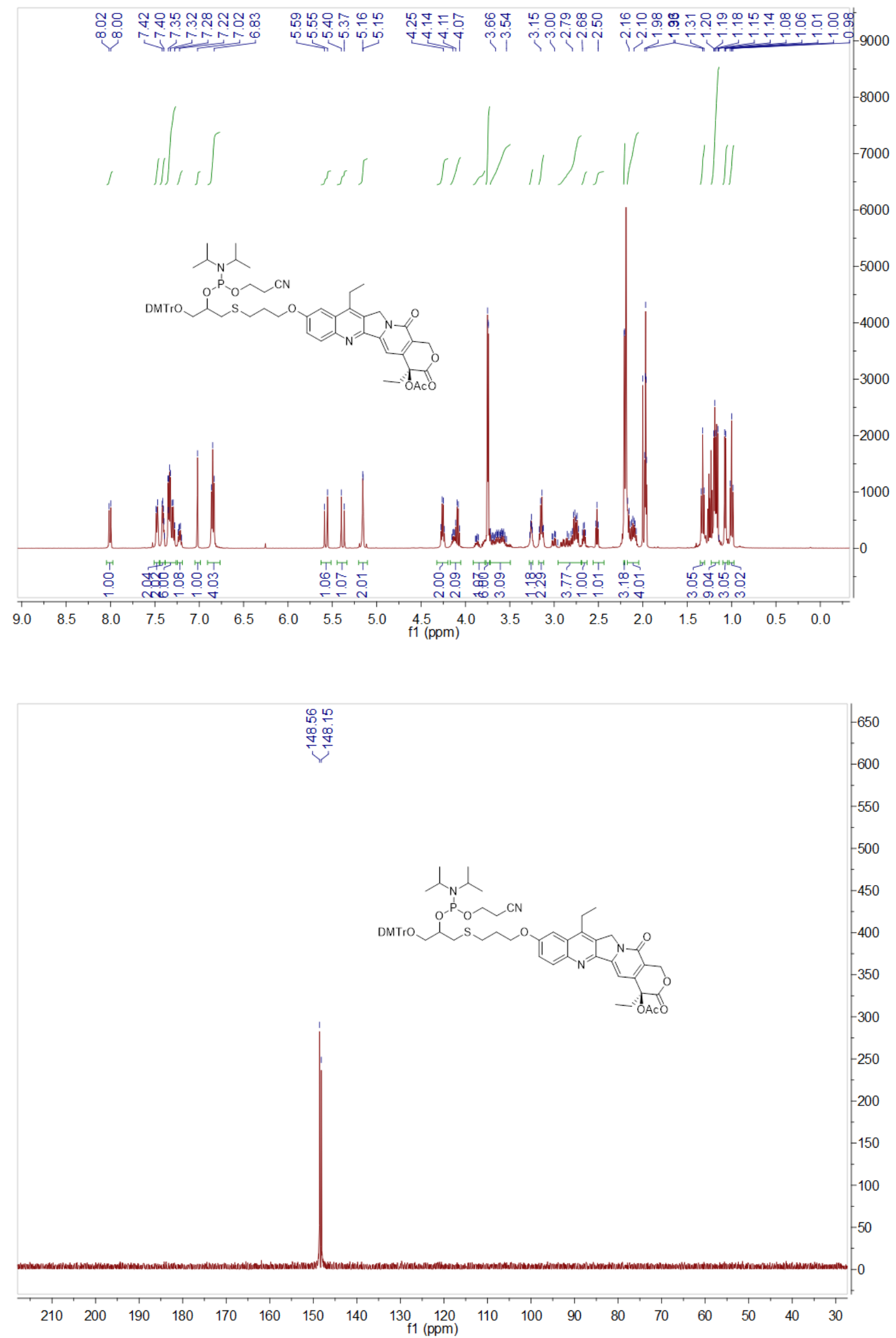


\section{Compound 11}
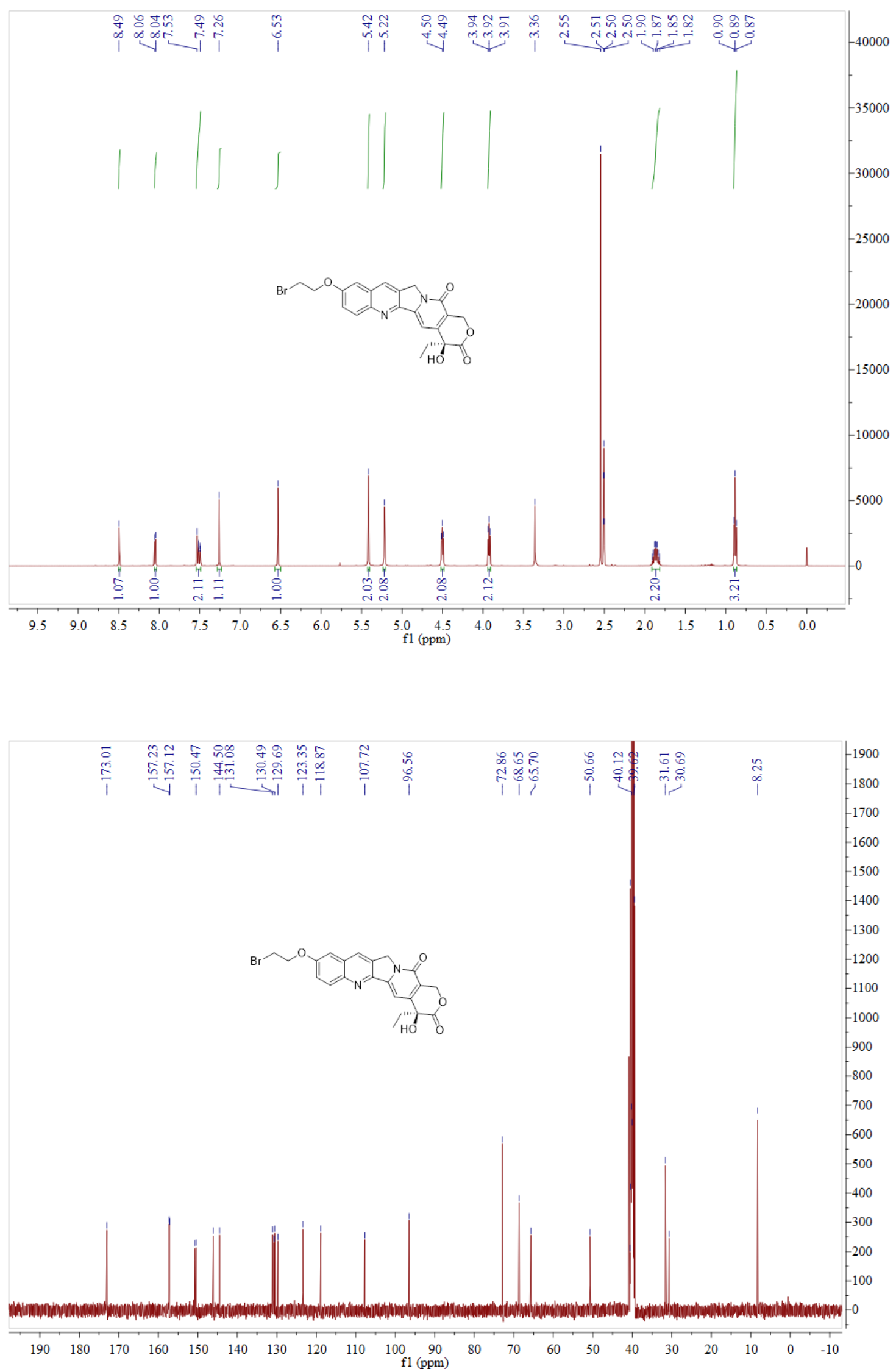


\section{Compound 12}
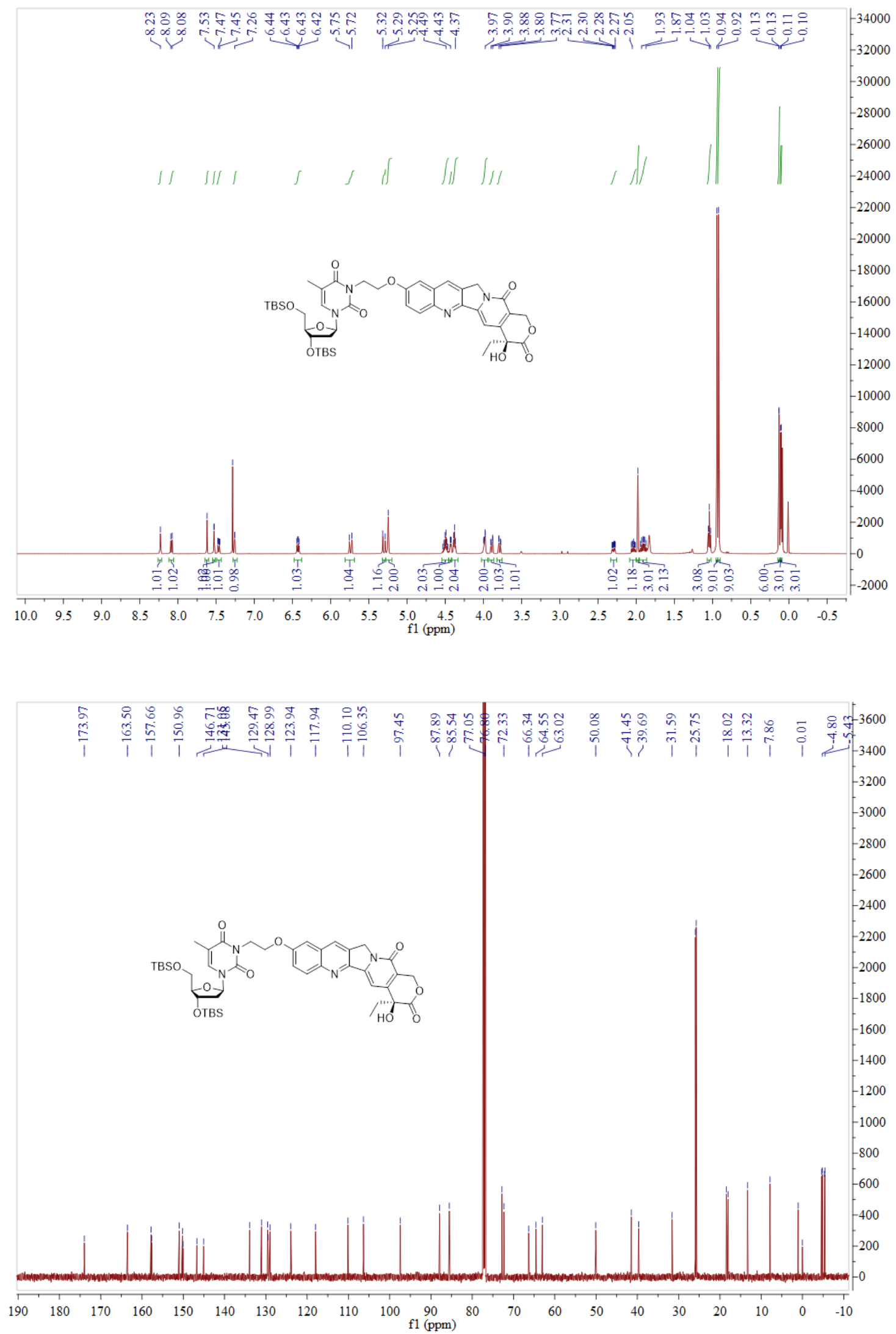


\section{Compound 13}
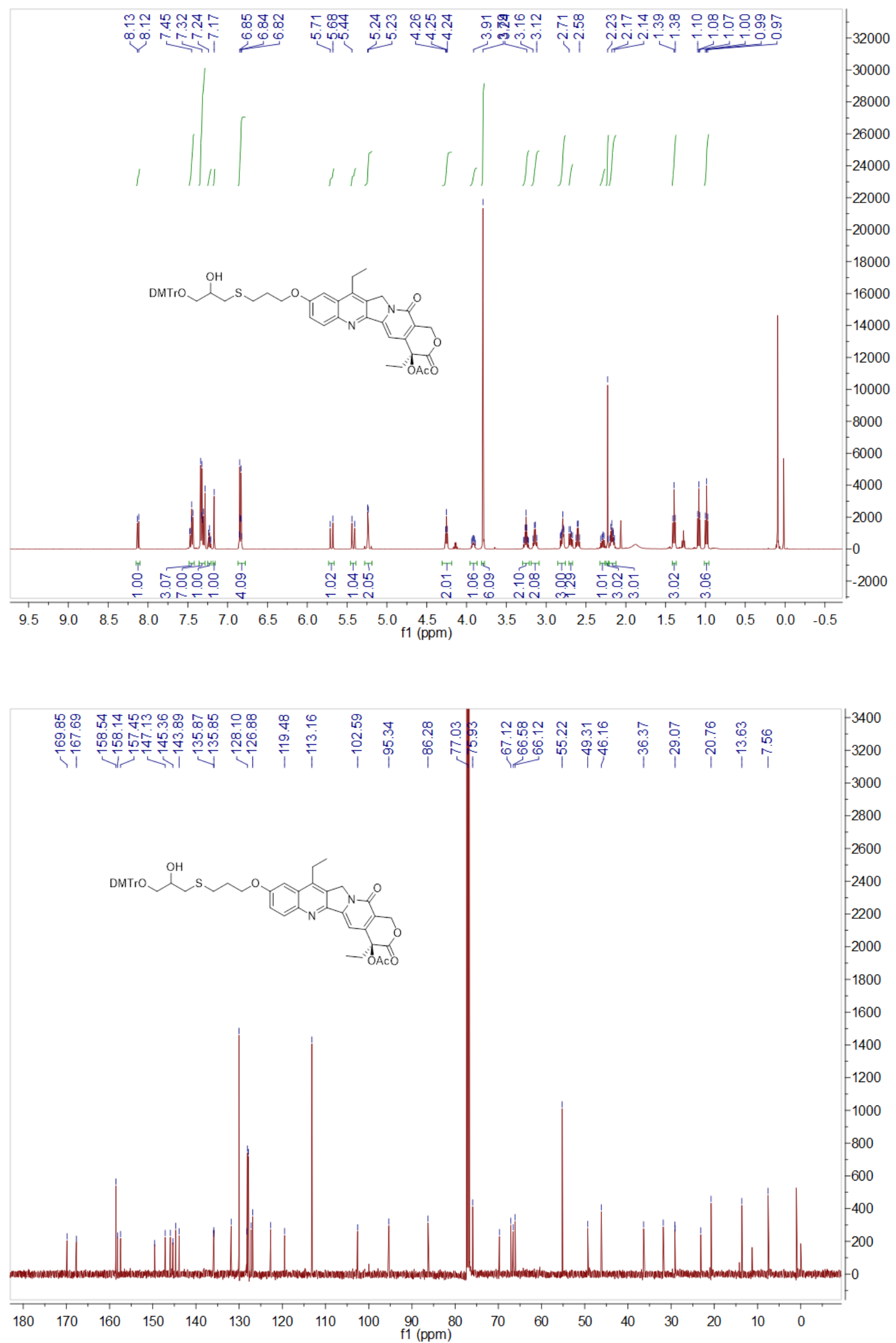